\title{
Quem é Classe Média no Brasil? Um Estudo sobre Identidades de Classe*
}

\author{
André Ricardo Salata \\ Pontifícia Universidade Católica do Rio Grande do Sul (PUC-RS), Rio Grande do Sul, Porto \\ Alegre, Brasil. E-mail: andre.salata@pucrs.br
}

\section{INTRODUÇÃO}

T os últimos anos, tornou-se comum no Brasil ler, ouvir e discutir a 1 respeito da chamada "nova classe média brasileira", a já famosa "classe C". O debate sobre esse tema foi impulsionado primeiramente pela publicação dos resultados de uma pesquisa da Fundação Getulio Vargas (FGV), coordenada pelo economista Marcelo Neri, na qual se afirmava que em 2008 o Brasil havia se tornado um "país de classe média". Tal conclusão decorria da constatação de que entre os anos de 2003 e 2008, devido aos então recentes avanços socioeconômicos do país (Barros et al., 2010), a maior parte da população brasileira já se encontrava na camada intermediária de renda - a "classe $C$ ". O estudo da FGV (Neri, 2008) chamava a atenção para o fato de que nos últimos anos milhares de indivíduos e famílias, que antes se encontravam nas camadas inferiores da escala de distribuição de renda, haviam atingido os níveis intermediários e, dessa maneira, foram identificados por

\footnotetext{
* Gostaria de agradecer à Celi Scalon, pela orientação ao trabalho de tese que originou este artigo, e a Marcelo Gomes Ribeiro pela leitura e sugestões feitas ao texto. Agradeço também a Bolívar Lamounier e ao Centro de Estudos de Opinião Pública (Cesop) da Universidade Estadual de Campinas (Unicamp) por disponibilizar a base de dados utilizada. As críticas e sugestões dos dois pareceristas anônimos da revista DADOS também foram muito importantes para chegarmos à versão final. De todo modo, sou inteiramente responsável pelos resultados, argumentos e conclusões.
}

DADOS - Revista de Ciências Sociais, Rio de Janeiro, vol. 58, no1, 2015, pp. 111 a 149. 
Neri (ibidem:5) como a "nova classe média brasileira", cuja emergência teria permitido ao Brasil tornar-se "um país de classe média"1.

A pesquisa da FGV lançou luzes sobre uma grande transformação socioeconômica que, de fato, tem estado em curso na sociedade brasileira nos últimos anos. Entre 2002 e 2008, milhares de indivíduos e famílias obtiveram aumentos substantivos em seus rendimentos e, como consequência, houve um crescimento importante de seu poder de consumo ${ }^{2}$. Essas pessoas atingiram níveis de rendimentos intermediários e passaram a fazer parte da camada da população que mais se assemelha ao "brasileiro mediano" - não somente em termos de renda, mas também no que se refere à educação, ocupação etc. ${ }^{3}$ Baseando-se neste fato, Neri (2008) denominou essa camada social de "classe média no sentido estatístico".

Iniciada, portanto, com a publicação dos resultados da pesquisa da FGV (Neri, 2008) e posteriormente seguida por autores como Souza e Lamounier (2010), a "tese da nova classe média brasileira", apesar de seu enorme sucesso nos meios de comunicação de massa (foram muitas as reportagens em jornais impressos, na internet, rádio e televisão a respeito da "classe $C^{\prime}$ ) foi fortemente criticada por alguns autores (como por exemplo, Souza, 2010; Sobrinho, 2011). As críticas, que em geral provinham do campo da sociologia, tinham como principal alvo o critério adotado por Neri (2008) para definir a "classe média" - somente a renda -, sob o argumento de que, segundo outras características, como categorias ocupacionais (Sobrinho, 2011; Pochman, 2012) e/ ou capital cultural (Souza, 2010), aquele contingente de pessoas não poderia ser considerado "classe média". Na esteira desse tipo de argumentação, também publicamos alguns trabalhos problematizando a tese da "nova classe média brasileira" pelo prisma sociológico (Scalon e Salata, 2012; Salata, 2012).

Em nossa opinião, a polêmica entre a perspectiva sociológica, mais estrutural, e a perspectiva econômica, mais focada nos rendimentos, deve ser aprofundada, e pode gerar resultados interessantes. No entanto, o empenho em desenvolver o presente trabalho surgiu da percepção de que, para além do embate entre essas duas perspectivas, outra importante disputa tem sido travada desde a divulgação da pesquisa da FGV. Trata-se de um embate que não poderia ser compreendido nem pelo prisma econômico de Neri (2008), nem pela perspectiva sociológica que o vinha criticando (Sobrinho, 2011; Souza, 2010; Scalon e Salata, 2012). 
Referimo-nos a uma grande discussão a respeito da própria definição da classe média brasileira. Afinal, quem se identifica, e é por sua vez reconhecido como classe média no Brasil? Essa é a questão principal que trataremos no presente artigo. Assim, apesar de reconhecermos a importância do debate a respeito das vantagens e desvantagens de utilizar diferentes critérios e variáveis - como ocupação ou renda - para a análise das desigualdades econômico-sociais, não temos, nesse trabalho, a intenção de tomar uma posição nesta discussão ${ }^{4}$. Para além dela, procuraremos chamar a atenção para a importância de analisar como os próprios indivíduos percebem sua posição socioeconômica.

Para examinar essa questão, usaremos metodologia quantitativa que será detalhada mais adiante. Antes de apresentar a análise empírica, faremos, na próxima seção, alguns breves comentários a respeito da literatura recente sobre identidades de classe.

\section{IDENTIDADES DE CLASSE E CLASSE MÉDIA NO BRASIL}

Podemos identificar, na literatura sociológica, um grande número de trabalhos a respeito dos aspectos subjetivos da estratificação social, em especial no que se refere à consciência (ou identidade) de classes ${ }^{5}$. Tradicionalmente, a maior parte das pesquisas sobre identidade/consciência de classe baseava-se na famosa abordagem "S-C-A" (Structure-Consciousness-Action), de maneira que a esfera subjetiva era vista somente como uma consequência - necessária ou contingente - da estrutura objetiva (Devine e Savage, 2005). Nos últimos anos, entretanto, uma nova abordagem tem lançado dúvidas sobre essas ideias, atribuindo maior importância aos aspectos subjetivos e tomando-os não somente como uma consequência da estrutura objetiva, mas também como uma dimensão independente da estratificação que teria, por sua vez, consequências reais para a própria formação das classes sociais (Devine et al., 2005; Charlesworth, 2000; Skeggs, 1997; Reay, 2005) ${ }^{6}$.

Com efeito, essa nova abordagem procura enfatizar as qualidades independentes das identidades de classe. Essas são tomadas não como etiquetas de dadas posições objetivas, mas sim como reivindicações de pertencimento e reconhecimento que são contestadas e disputadas. Assim, ao invés de interpretar os dados sobre localização subjetiva como um indicador que mediria o grau de "consciência" dos indivíduos em relação à sua posição objetiva, a identidade de classe é tomada como uma reivindicação de pertencimento a grupos sociais, e tais rei-

DADOS - Revista de Ciências Sociais, Rio de Janeiro, vol. 58, no 1, 2015 
vindicações poderiam ser endossadas ou negadas por outros indivíduos / grupos, o que caracterizaria as disputas em relação às formações de classe.

Dessa maneira, as ambivalências presentes nos resultados de estudos sobre a consciência/identidade de classe são analisadas em seus próprios termos, sem tomar parâmetros supostamente "corretos" como referência. Como as identidades de classe não são vistas somente como consequência das condições econômicas, mas também como reivindicações de pertencimento, não seria possível afirmar que um indivíduo não é "consciente" de sua posição, ou que ele possui uma consciência falsa ou equivocada, ou uma percepção "distorcida" de sua localização social. Nesse sentido, a identidade de classe de um indivíduo não seria um reconhecimento - correto ou distorcido - de sua "verdadeira" posição; tratar-se-ia, na verdade, de uma maneira de se diferenciar ou aproximar de outros, um modo de afirmar a que classe de indivíduos gostaria de estar próximo, e das quais pretenderia se distinguir.

Já que a subjetividade não é mensurada por um parâmetro objetivo, mas constitui uma informação importante por si mesma, tem havido uma crescente reorientação da ideia de "consciência de classe" em direção à noção de "identidade" (Devine e Savage, 2005). Essa reorientação pode ser verificada nos trabalhos de autores como Devine (1992); Scott (1996); Charlesworth (2000); Savage et al. (2001) e Lammont (1992).

As identidades são compreendidas, portanto, como um processo em eterno movimento, nunca acabado, nunca resolvido, envolvendo o constante entendimento de quem somos e de quem as outras pessoas são, e, reciprocamente, o entendimento de outras pessoas sobre elas mesmas e sobre os outros ${ }^{7}$. Ou seja, o processo de identificação diria respeito ao sistemático estabelecimento e significação de relações de similaridade e diferença. Afinal, dizer quem eu sou é dizer quem eu não sou (diferença), e também dizer com quem creio ter coisas em comum (similaridade). Com efeito, seria através do processo de identificação que criaríamos a noção de "nós" e "eles" (Jenkins, 1996)

Tal processo envolveria sempre, portanto, disputas e negociações, num constante jogo de forças, e se daria através de afirmações, resistência, reivindicações, aceitação, imposição etc., em uma contínua relação entre seu momento interno (autoidentificação) e externo (categorização) ${ }^{9}$. Nesse sentido, a literatura recente busca interpretar as 
identidades de classe como parte de um processo de constantes disputas e negociações que envolvem tanto classificações quanto autoidentificações ${ }^{10}$.

Essa literatura tem reconhecido, portanto, a necessidade de considerar ambos os aspectos - objetivo e subjetivo - da estratificação. Classes sociais são entendidas não (somente) como um agregado de posições objetivas, mas (também) como "[um] rótulo aplicado a um nexo de relações desiguais decorrentes da organização social da produção, distribuição, troca e consumo" (Bradley, 1996:46; tradução livre). Seria o próprio processo de identificação que - entre outros fatores - unificaria situações socioeconômicas relativamente heterogêneas, e que de outra maneira seriam um mero agregado de indivíduos ocupando posições objetivas similares ${ }^{11}$.

Além disso, conforme lembrado por parte dessa literatura (Skeggs, 1997; Savage et al., 2001; Eijk, 2012; Reay, 2005; Sayer, 2005), uma importante característica das identidades de classe seria seu conteúdo moralmente carregado. Argumenta-se que a ideia de pertencimento a diferentes classes estaria relacionada à percepção de uma distribuição desigual de reconhecimento social. Identificações de classe, portanto, além de diferenciar os indivíduos, também imprimiriam uma hierarquia a essa diferenciação, e por esse motivo não seriam propriamente classificações neutras, mas hierarquias de valor.

Tomaremos então as informações subjetivas não como percepções corretas ou equivocadas de uma definição de classe média a priori estabelecida por nós, mas como reivindicações de pertencimento, que participam ativamente na própria formação, manutenção e questionamento dos contornos e fronteiras que definem a classe média no Brasil.

Na verdade, a questão das identidades de classe sempre foi fundamental no debate a respeito da(s) classe(s) média(s). Seja colocando-a em segundo plano, seja atribuindo-lhe um papel central, grande parte dos autores que trataram do tema da classe média tiveram que lidar com a esfera subjetiva. Algumas perspectivas têm, inclusive, se concentrado nessa esfera como uma maneira de enfrentar a principal questão - ou dificuldade - que perpassa todo debate em torno da classe média, que é o de sua formação enquanto categoria socialmente significativa (Butler e Savage, 1995), ou a identificação/definição de seus contornos (Wacquant, 1992).

DADOS - Revista de Ciências Sociais, Rio de Janeiro, vol. 58, nº 1, 2015 
Isso nos leva à principal questão deste artigo, que é analisar se aqueles indivíduos que ocupam posições intermediárias se identificam tipicamente na posição de classe média, ou se, numa hipótese alternativa, essa identificação seria mais comumente encontrada entre os mais abastados. Dessa maneira, queremos entender como os próprios indivíduos percebem sua posição, e qual o "perfil socioeconômico" que no Brasil mais tipicamente se identifica (e, por sua vez, é reconhecido) como "classe média". Além disso, procuraremos também analisar qual imagem os brasileiros têm dessa classe.

Nossa hipótese alternativa é sustentada por parte da literatura sociológica mais recente a respeito da classe no Brasil (Owensby, 1999; $\mathrm{O}^{\prime}$ Dougherty, 2002) ${ }^{12}$. Dado o caráter periférico da sociedade brasileira, já tão bem caracterizado e analisado (Fernandes, 1975), a noção de "classe média" foi introduzida por aqui tardiamente, de fora para dentro. Importada do chamado "mundo desenvolvido" - Estados Unidos e, principalmente, Europa - nas primeiras décadas do século XX, e incorporada pelas camadas médio-superiores urbanas, que buscavam uma identidade social em meio às grandes transformações pelas quais o país passava, a concepção de "classe média" presente no Brasil se traduziria em uma imagem idealizada da classe média do "mundo desenvolvido", à qual somente as camadas mais abastadas da população brasileira poderiam corresponder. Buscaremos, no decorrer do artigo, testar esta hipótese.

\section{DADOS E MÉTODOS}

A fim de conduzir as análises empíricas neste artigo, analisaremos os dados provenientes do "survey sobre a classe média", produzido no Brasil no ano de 2008, que traz dados nacionais representativos sobre identidade de classes, percepções sobre estrutura social e informações socioeconômicas - como renda, educação etc. O survey foi conduzido em 141 cidades, entre os dias 8 e 12 de setembro, e sua amostra é representativa para a população brasileira com 16 anos ou mais de idade, contendo $2.002 \operatorname{casos}^{13}$. O critério de seleção foi probabilístico nos dois primeiros estágios (cidades e agregados geográficos), e para a seleção dos entrevistados no terceiro estágio foram utilizadas cotas de gênero, idade, escolaridade e setor de atividade. A margem de erro estimada é de dois pontos percentuais para os resultados do total da amostra ${ }^{14}$.

Com o uso de estatísticas descritivas e modelos multivariados, buscaremos testar a hipótese de que, no Brasil, os indivíduos mais abastados 
(perfil $\mathrm{AB}$ ) - e não aqueles estatisticamente intermediários (perfil C) seriam os que tipicamente se identificam com a classe média; além disso, analisaremos a percepção dos brasileiros sobre essa classe e sobre as características que lhes parecem mais importantes para uma pessoa fazer parte dela.

\section{RESULTADOS}

A base de dados do "survey sobre a classe média", que usaremos nesta seção, traz duas variáveis principais relacionadas com a questão das identidades de classe. Em primeiro lugar, os entrevistados deviam responder à seguinte pergunta, sem qualquer categoria de resposta prédefinida: "hoje em dia muito tem se falado sobre classes sociais. A qual classe vocêacha que você pertence?". As respostas dadas foram codificadas nas seguintes categorias: classe alta, classe média alta, classe média, classe média baixa, classe trabalhadora, classe baixa / pobre e nenhuma classe. Em seguida, os entrevistados deviam responder à seguinte questão: "e, entre a lista de opções abaixo (classe alta, classe média alta, classe média, classe média baixa, classe trabalhadora, classe baixa/pobre e nenhuma classe), a qual classe você acha que você pertence?" Ou seja, havia primeiramente uma pergunta aberta, e, em seguida, uma pergunta estimulada em que as categorias de respostas eram pré-formuladas.

Trabalharemos neste artigo somente com as identidades de classe "espontâneas". Já que estamos analisando identidades de classe na qualidade de reivindicações de pertencimento, acreditamos ser mais adequado investigar como as pessoas se classificam "espontaneamente", o que pode ser considerado um indicador melhor do que as respostas estimuladas - quando suas alternativas de resposta são dadas a priori.

Segundo os dados apresentados no Gráfico 1, a maior parte dos brasileiros se identifica como classe baixa $(32,6 \%)$, seguidos por aqueles que se reconhecem como classe média $(24,5 \%)$, classe trabalhadora $(19,1 \%)$, classe média baixa $(16,2 \%)$, nenhuma classe $(6 \%)$, classe média alta $(1,5 \%)$ e, finalmente, classe alta (menos de $1 \%)$ :

Assim, a maior parte dos brasileiros se vê entre a classe baixa / pobre e a "classe média". É importante ressaltar, desde já, a pequena porcentagem de pessoas que se classificam como classe média alta ou classe alta, o que pode ser um primeiro indicador de que, no Brasil, a classe média é tomada quase como um limite superior.

DADOS - Revista de Ciências Sociais, Rio de Janeiro, vol. 58, nº 1, 2015 
Gráfico 1

Frequência das Identidades de Classe

(Brasil, 2008)

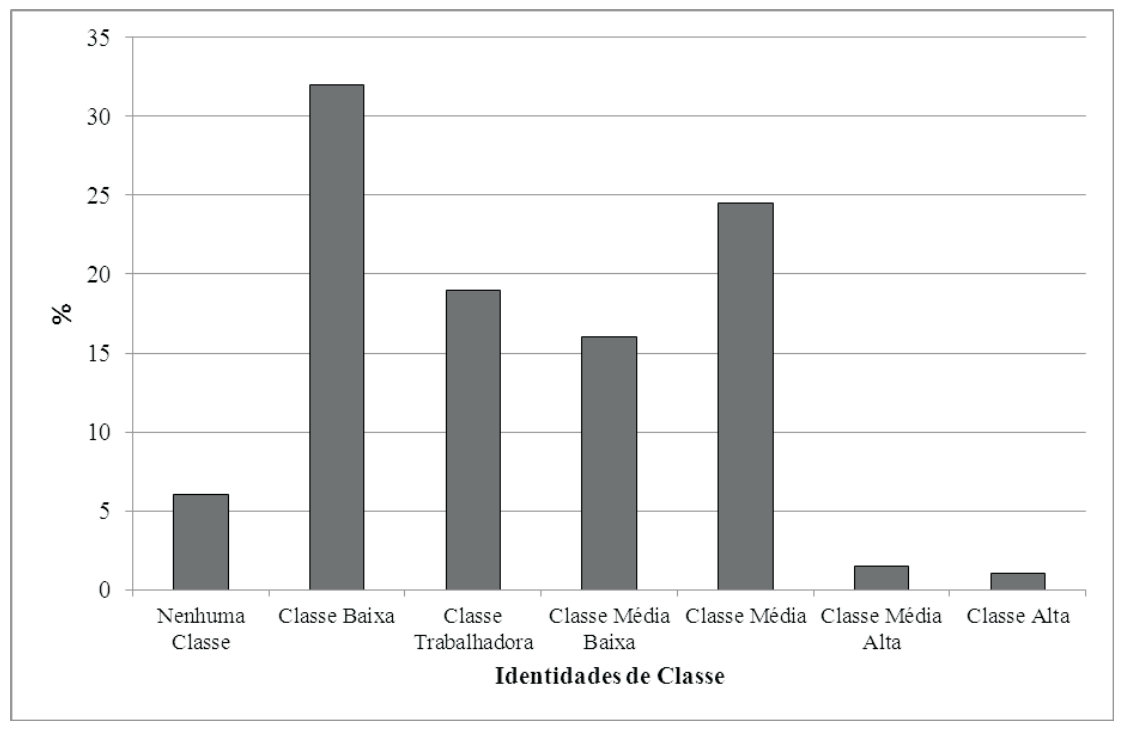

Fonte: Pesquisa sobre a Classe Média 2008 (Banco de Dados, Cesop/Unicamp). Disponível em: http://www.cesop.unicamp.br/site/htm/busca/php. Acessado em 5/6/2012. Tabulação do próprio autor.

Com o objetivo de estudar a relação entre as identidades de classe e o nível socioeconômico dos indivíduos, trabalharemos com quatro variáveis: rendimentos, nível de escolaridade, categoria ocupacional e tipologia de consumo. Nos próximos parágrafos teceremos breves comentários sobre as variáveis utilizadas, na intenção de facilitar a interpretação dos resultados.

Devido à natureza original da variável "rendimentos" da base de dados, as faixas de renda com que trabalhamos não coincidem exatamente com aquelas construídas por Neri (2008). Nosso intervalo de renda "E" é formado pelas pessoas com rendimento domiciliar total mensal de até $\mathrm{R} \$ 726,00$; o nível “ $\mathrm{D}$ ” agrega os que têm renda entre $\mathrm{R} \$ 726,01$ e $\mathrm{R} \$ 1.195,00$, o que é próximo da mediana da distribuição em 2008 (que se situava em $\mathrm{R} \$ 1.245,00)$; o nível " $\mathrm{C}$ ", por sua vez, agrega as pessoas com renda entre $\mathrm{R} \$ 1.195,01$ e $\mathrm{R} \$ 3.474,00$ (valor que delimita aproximadamente os $15 \%$ mais ricos no Brasil em termos de renda domiciliar); por fim, acima deste último valor, fica o nível " $A B^{\prime \prime 15}$. Ou seja, a principal diferença de nossas faixas de renda em relação àquelas utilizadas por Neri (2008) é que o nosso limite superior da "camada C" - ou 


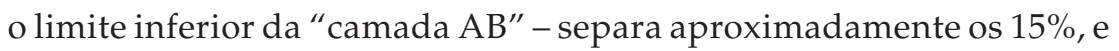
não os $10 \%$, mais abastados.

Apesar de os níveis de rendimentos serem informações socioeconômicas muito importantes, outros dados, como nível educacional e categoria ocupacional, podem fornecer uma ideia mais confiável da posição social dos indivíduos, já que tornam possível acessar os mecanismos mais estruturais que explicam as desigualdades de renda (Wright, 2005; Goldthorpe, 2009; Crompton, 2010). É por essa razão que, além dos rendimentos, também iremos trabalhar com categorias ocupacionais e anos de escolaridade.

A classificação ocupacional aqui adotada deriva do famoso EGP (Erikson et al., 1979) ${ }^{16}$. Para construir as categorias, trabalharemos com as informações ocupacionais dos chefes de domicílio ${ }^{17}$. Seguindo as instruções oferecidas por Ganzeboom e Treiman (1996), classificamos as informações ocupacionais nas seguintes categorias: trabalhador rural; trabalhador manual não qualificado ou semiqualificado; trabalhador manual qualificado; trabalhador não manual de rotina; e profissionais e administradores ${ }^{18}$. Já os anos de escolaridade, por sua vez, foram categorizados da seguinte maneira: até 5 anos de estudo; de 5 a 8 anos de estudo; de 9 a 11 anos de estudo; e 12 ou mais anos de estudo.

Felizmente, além das informações sobre rendimentos, educação e ocupação, a base de dados do survey sobre a classe média também traz algumas informações a respeito do padrão de consumo dos entrevistados. Mais precisamente, eles deviam responder, separadamente, se estavam planejando comprar uma casa, um carro, mobília e eletrodomésticos nos próximos 12 meses. Além disso, se tinham plano de saúde particular, previdência privada, poupança/investimentos, filhos estudando em escolas/universidades privadas, e se haviam ido ao teatro ou viajado para o exterior nos últimos 12 meses.

Com o objetivo de facilitar a utilização deste conjunto de variáveis ${ }^{19}$, criamos uma tipologia. O primeiro passo foi a aplicação de uma Análise de Correspondência Múltipla; a partir dela, extraímos os dois primeiros eixos, que juntos explicavam $39,8 \%$ da inércia. Posteriormente, salvamos as coordenadas dos indivíduos nas duas dimensões extraídas e utilizamos essas informações em uma análise de Cluster $^{20}$, que resultou na criação de três "tipos" de indivíduos. Como se pode ver no Gráfico 7 (Anexo), o primeiro tipo - "baixo" - é caracterizado pela não participação nas práticas de consumo analisadas; o segundo - "inter-

DADOS - Revista de Ciências Sociais, Rio de Janeiro, vol. 58, no 1, 2015 
mediário" -, apresenta uma tendência a participar dessas práticas, mas especialmente naquelas relacionadas a bens de consumo como casa, mobília e eletrodomésticos; por fim, o terceiro tipo - "alto" - é caracterizado pela tendência a participar de todas as práticas e, principalmente, daquelas de caráter mais distinto - como viagens internacionais, educação particular, plano de saúde, poupança etc.

O Gráfico 8 do Anexo, traz o cruzamento entre as variáveis socioeconômicas (rendimentos, nível de escolaridade, categoria ocupacional e tipologia de consumo) com as identidades de classe. Conforme podemos verificar, se por um lado as categorias inferiores apresentam uma clara tendência de identificação com a "classe baixa / pobre", por outro a identificação com a "classe média" é destacadamente mais comum entre "profissionais" e "administradores", pessoas com rendimentos elevados (AB), 12 anos ou mais de escolaridade, e práticas de consumo distintas. Entre as categorias intermediárias, no entanto, a distribuição das identidades de classe é mais "apagada", menos clara, de modo que nenhuma categoria se destaca das demais.

A fim de analisar e expor as relações entre identidades de classe, nível de escolaridade, intervalos de renda, categorias ocupacionais e práticas de consumo de maneira integrada, facilitando a exploração dos dados, rodamos uma Análise de Correspondência Múltipla ${ }^{21}$, resultando em dois eixos extraídos que, juntos, explicavam $75 \%$ da inércia (variação), sendo $47 \%$ explicados pelo primeiro eixo e $28 \%$ pelo segundo. Apresentamos a seguir o Gráfico 2 formado por esses dois fatores ${ }^{22}$.

Como se pode ver no Gráfico 2, o primeiro eixo ordena as categorias desde o intervalo de renda " $A B^{\prime}$, " 12 ou mais" anos de escolaridade, tipo "alto" de consumo e "profissionais e administradores" - à direita - até o intervalo de renda " $E$ ", " 0 a 4 " anos de escolaridade, tipo de consumo "baixo" e "trabalhadores rurais" ou "inativos e desempregados" - à esquerda. Ou seja, este fator discrimina, em termos de nível socioeconômico, do mais alto para o mais baixo - da direita para a esquerda, respectivamente. Já em relação ao segundo eixo, enquanto as categorias intermediárias se encontram na parte superior, as categorias extremas - baixas ou altas - estão na parte inferior. Ou seja, esse segundo eixo separa as categorias intermediárias das demais.

Podemos então identificar quatro "tipos" no Gráfico 2: o primeiro, localizado no quadro inferior à esquerda, possui rendimentos baixos $(\mathrm{E})$ e pouca escolaridade (0-4), tende a não participar nas práticas de con- 
Gráfico 2

Análise de Correspondência Múltipla** (categories plot): Identidades de Classe*, Categorias Ocupacionais, Tipologia de Consumo, Anos de Escolaridade e Intervalos de Renda (Brasil, 2008)

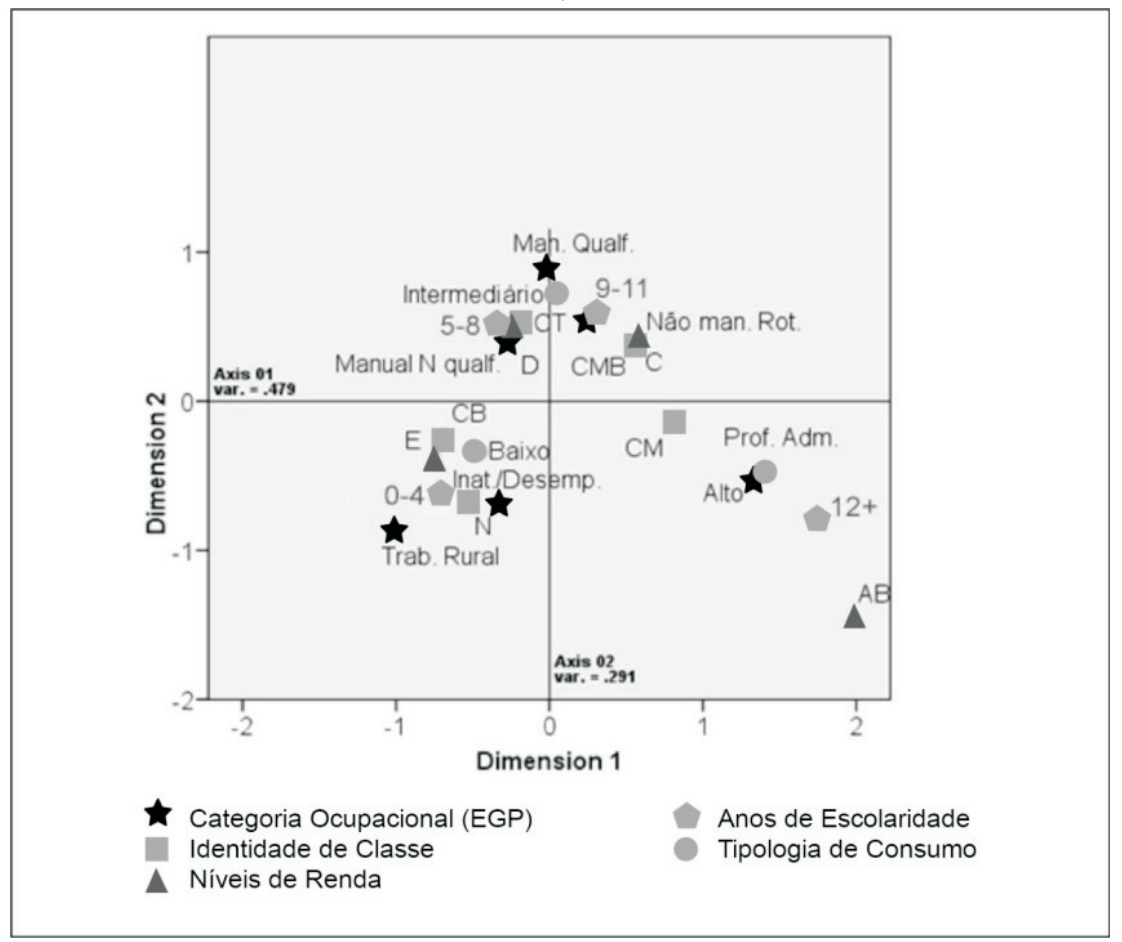

Fonte: Pesquisa sobre a Classe Média 2008 (Banco de Dados, Cesop/Unicamp). Disponível em http://www.cesop.unicamp.br/site/htm/busca/php. Acessado em 5/6/2012. Tabulação do próprio autor.

${ }^{*}$ Classe Média (CM); Classe Média Baixa (CMB); Classe Trabalhadora (CT); Classe Baixa / Pobre (CB); Nenhuma Classe (N).

**Normalização: variáveis principais

sumo analisadas (baixo), está na categoria de "trabalhador rural" (ou "inativo/desempregado") e se percebe como "classe baixa/pobre"; o segundo tipo, localizado no quadro superior à esquerda, possui rendimentos na faixa " $\mathrm{D}$ ", " 5 a 8" anos de escolaridade, tende a participar das práticas de consumo (intermediário), se encontra na categoria de "trabalhador manual não qualificado" e se percebe como "classe trabalhadora"; o terceiro, por sua vez, localizado no quadro superior à direita, possui rendimentos intermediários (C), "9 a 11" anos de escolaridade, tipo "intermediário" de consumo, ocupação "não manual de rotina" e se identifica com a "classe média baixa"; finalmente o quarto 
tipo, localizado no quadro inferior à direita, apresenta rendimentos altos (AB), "12 ou mais" anos de escolaridade, está na categoria dos "profissionais ou administradores", participa de práticas distintas de consumo (tipo "alto") e se identifica com a "classe média".

Assim, verificamos que o tipo "E" está mais perto da identidade de "classe baixa/pobre", o " $\mathrm{D}$ " está mais próximo da identidade de "classe trabalhadora", o "C" encontra-se mais próximo da identidade de

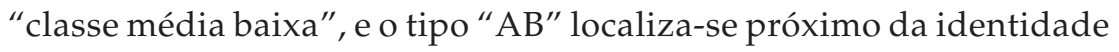
de "classe média".

Um fato interessante a se observar no Gráfico 2: as categorias de nível socioeconômico superior encontram-se tão distantes da identidade de "classe média" quanto as categorias "intermediárias". Isso ilustra o fato de que o nível " $A B$ " é o único que está completamente distante de outras identidades de classe que não a identidade de "classe média". Assim, apesar de podermos encontrar uma proporção substantiva de indivíduos se identificando como "classe média", no perfil " $\mathrm{C}$ ", por exemplo, também podemos encontrar uma grande proporção de pessoas se reconhecendo como "classe baixa / pobre", "classe trabalhadora" e, especialmente, "classe média baixa" nesse perfil. Mas é somente entre os indivíduos do perfil "AB" que a identidade de "classe média" ofusca todas as outras, fazendo deste tipo algo muito mais "fechado" e unificado em sua identidade de classe (média).

Com efeito, a análise acima nos fornece um quadro geral, e bastante relevante, da relação entre posição social e identidade de classe no Brasil. Além disso, já serve também como forte indicador de que é somente entre os indivíduos que ocupam posições superiores (com renda alta, educação universitária, ocupação de prestígio e consumo distinto) que encontramos uma forte e clara identificação com a classe média.

A Análise de Correspondência Múltipla, entretanto, não testa nossas hipóteses de uma maneira formal. Para fazer isso de modo mais apropriado, também trabalhamos com análise de regressão (logit multinomial $^{23}$ ), tomando as "identidades de classe" como variável dependente, na intenção de examinar as diferenças nas chances (e probabilidades) de identificação com a "classe média" de acordo com as variáveis de nível socioeconômico.

O Quadro 1 descreve as variáveis utilizadas em nossos modelos ${ }^{24}$, e a Tabela 2 - em anexo - apresenta a descrição dos modelos rodados e suas respectivas estatísticas de ajuste ${ }^{25}$. 
Quadro 1

Modelos Multinomiais para Identidades de Classe: Descrição das Variáveis (Brasil, 2008)

\begin{tabular}{|c|c|c|c|}
\hline Posição & Nome & Tipo & Categorias/Unidades \\
\hline \multirow{9}{*}{ 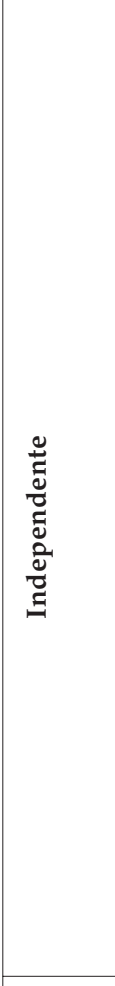 } & Idade & Contínua & Anos \\
\hline & Região Geográfica & Dummies & $\begin{array}{l}\text { Reg1: NO/CO (ref=Sul) } \\
\text { Reg2: NE (ref=Sul) } \\
\text { Reg3: SE (ref=Sul) }\end{array}$ \\
\hline & \multirow{2}{*}{ Localização } & \multirow{2}{*}{ Dummies } & Loc1: Cap. (ref=int) \\
\hline & & & Loc2: Per. (ref=int) \\
\hline & Gênero & Dummy & Gênero: Masc. $(\mathrm{ref}=\mathrm{fem})$ \\
\hline & Escolaridade & Dummies & $\begin{array}{l}\text { Esc1: 0-4 }(\mathrm{ref}=12+) \\
\text { Esc2: } 5-8(\mathrm{ref}=12+) \\
\text { Esc3: 9-11 (ref=12+) }\end{array}$ \\
\hline & Tipologia de Consumo & Dummies & $\begin{array}{l}\text { Tipo1: baixo (ref=alto) } \\
\text { Tipo2: interm. (ref=alto) }\end{array}$ \\
\hline & Renda & Dummies & $\begin{array}{l}\text { Renda1: } \mathrm{E}(\mathrm{ref}=\mathrm{AB}) \\
\text { Renda2: } \mathrm{D}(\mathrm{ref}=\mathrm{AB}) \\
\text { Renda3: } \mathrm{C}(\mathrm{ref}=\mathrm{AB})\end{array}$ \\
\hline & $\begin{array}{c}\text { Categoria Ocupacional } \\
\text { (EGP) do Chefe de } \\
\text { Domicílio }\end{array}$ & Dummies & $\begin{array}{l}\text { Ocup1: Inativos (ref=Prof. Adm.) } \\
\text { Ocup2: Trab. Rural (ref=Prof. Adm.) } \\
\text { Ocup3: Trab. Manual N-Qualif. } \\
\text { (ref=Prof. Adm.) } \\
\text { Ocup4: Trab. Manual Qualif. (ref=Prof. } \\
\text { Adm.) } \\
\text { Ocup5: Trab. Não Manual de Rotina } \\
\text { (ref=Prof. Adm.) }\end{array}$ \\
\hline 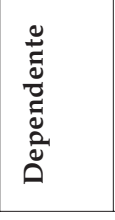 & $\begin{array}{l}\text { Identidade de Classe } \\
\text { (espontânea) }\end{array}$ & Categórica & $\begin{array}{l}\text { Classe Média } \\
\text { Classe Média Baixa } \\
\text { Classe Trabalhadora } \\
\text { Classe Baixa/Pobre (referência) } \\
\text { Nenhuma Classe }\end{array}$ \\
\hline
\end{tabular}

Obs.: Quadro elaborado pelo autor.

Na base do Quadro 1, vemos que nossa variável dependente possui cinco categorias: "nenhuma classe", "classe baixa/pobre" (categoria de referência) $)^{26}$, "classe trabalhadora", "classe média baixa" e "classe média". Entre as variáveis independentes, temos a idade (contínua, em anos), gênero (dummy), região geográfica (dummies), localização ${ }^{27}$ (dummies), renda domiciliar (dummies), anos de escolaridade (dummies), tipologia de consumo (dummies) e categorias ocupacionais (dummies). 
Por fim, a Tabela 3, em anexo, apresenta os parâmetros (razões de chance) estimados pelo modelo rodado (aquele que inclui todas as variáveis descritas acima). É possível verificar que possuir nível superior de escolaridade - ao invés de primário, fundamental ou secundário - aumenta as chances de os indivíduos adotarem uma identidade de qualquer outra classe que não seja a "classe baixa". Por exemplo, ter um nível "básico" de escolaridade ao invés de "superior" reduz em $77 \%$ as chances de adotar uma identidade de "classe média" em vez de "classe baixa". Além disso, possuir nível "secundário" de escolaridade em vez de "superior", reduz em $50 \%$ as chances de identificação com a "classe média", em lugar da "classe baixa" 28 .

O nível de rendimentos também se revelou muito importante. Até mesmo quando controlamos os efeitos das demais variáveis (como escolaridade e ocupação) é possível ver que o fato de um indivíduo estar na faixa " $\mathrm{C}$ " - e não na " $\mathrm{AB}$ " - reduz em $78 \%$ suas chances de adotar uma identidade de "classe média" em oposição à de "classe baixa"; e estar na faixa " $\mathrm{D}$ " reduz essas chances em mais de $90 \%$. Além disso, estar nas faixas " $C$ " ou " $D$ " (ao invés de " $A B$ ") também reduz, porém de maneira menos acentuada, as chances de os indivíduos se reconhecerem como "classe média baixa", e não "classe baixa".

Conforme esperado, variáveis como escolaridade, consumo e, principalmente, renda, produzem fortes efeitos sobre as identidades de classe. De uma maneira geral, a identidade de classe média está bastante associada à escolaridade superior, a um nível elevado de rendimentos $(\mathrm{AB})$ e a práticas distintas de consumo.

Mas, como o modelo multinomial trabalha com razões de chance, e dado o número de categorias na nossa variável dependente - há quatro parâmetros explícitos para cada variável independente --, seria muito difícil interpretar a grande quantidade de informações que o modelo fornece ${ }^{29}$. Além disso, como já deve estar claro, estamos interessados na relação entre identidades de classe e "perfis socioeconômicos", e não exatamente nos coeficientes relativos a variáveis específicas.

A fim de melhor atender aos objetivos do estudo e relativizar as dificuldades de interpretação impostas pelo modelo multinomial, faremos uso das probabilidades preditas (Long e Freese, 2006). Assim, a partir do nosso modelo, extraímos as probabilidades preditas das diferentes identidades de classe para quatro casos fictícios (simulados), empregados como proxies dos quatro diferentes tipos socioeconômicos (E, D, 
$\mathrm{C}$ e $\mathrm{AB})$, analisados anteriormente. Todos eles compartilham algumas características básicas, como: ter 35 anos de idade, ser do sexo masculino e viver em uma capital no sudeste do Brasil ${ }^{30}$. Por outro lado, eles são bastante diferentes no que se refere às características socioeconômicas.

O tipo “E” caracteriza-se por nível educacional baixo (0-4 anos), poder de consumo "baixo", nível "E" de rendimentos e situação ocupacional de "trabalhadores rurais"; o tipo " $\mathrm{D}$ ", por ter de 5 a 8 anos de escolaridade, poder de consumo "intermediário", encontrar-se na camada de renda " $\mathrm{D}$ " e na categoria ocupacional dos "trabalhadores manuais não qualificados"; o tipo "C" tem nível educacional médio (9-11 anos), poder de consumo "intermediário", rendimentos na faixa "C" e situação ocupacional de "trabalhadores não manuais de rotina"; por fim, o tipo "AB" apresenta nível "superior" de escolaridade (12 anos ou mais), poder de consumo "alto", encontra-se na camada " $A B$ " de rendimentos e na categoria ocupacional dos "profissionais e administradores".

Esses casos fictícios, simulações, podem ser vistos como proxies - ou tipos médios - dos diferentes perfis socioeconômicos agregados pelos intervalos de renda de Neri (2008), e também captados anteriormente por meio da Análise de Correspondência Múltipla.

O Gráfico 3 mostra as probabilidades preditas das identidades de classe para cada um desses tipos ${ }^{31}$. Podemos ver que, de acordo com as probabilidades preditas pelo modelo - representadas no Gráfico 3-, o tipo " $E$ " apresenta uma probabilidade de 0,55 de se reconhecer como "classe baixa / pobre", sendo caracterizado pela predominância desta categoria. A probabilidade da identidade de "classe baixa / pobre" diminui conforme caminhamos em direção aos outros tipos, chegando a 0,02 para o tipo " $A B$ ", no qual, por sua vez, encontramos uma predominância da identidade de "classe média" - probabilidade de 0,68. Enquanto o tipo " $\mathrm{AB}$ " é marcado pela identidade de "classe média" e o tipo "E" pela de "classe baixa", os tipos " $\mathrm{D}$ " e "C" não apresentam nenhuma probabilidade que se destaque das demais.

Se, por um lado, o tipo "E" se destaca pela alta probabilidade de identificação com a "classe baixa / pobre", o tipo "AB" se distingue pela predominância da identidade de "classe média". De fato, é somente para o tipo " $\mathrm{AB}$ " que a probabilidade predita para "classe média" ultrapassa 0,50 e que a probabilidade para "classe baixa" é menor que 0,10 .

DADOS - Revista de Ciências Sociais, Rio de Janeiro, vol. 58, nº 1, 2015 
Gráfico 3

Modelo Logit Multinomial para Identidades de Classe:

Probabilidades Preditas por Tipos Socioeconômicos

(Brasil, 2008)

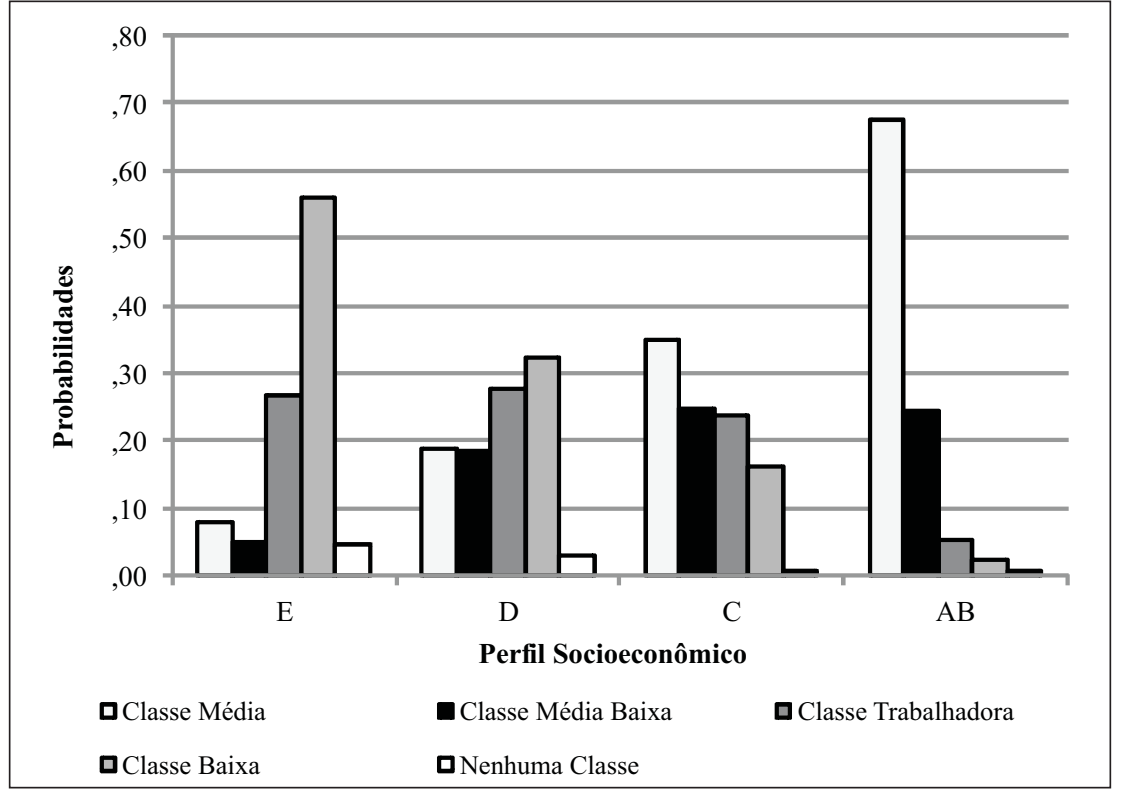

Fonte: Pesquisa sobre a Classe Média 2008 (Banco de Dados, Cesop/Unicamp). Disponível em: http://www.cesop.unicamp.br/site/htm/busca/php. Acessado em 5/6/2012. Tabulação do próprio autor.

Como vemos na Tabela 7 em anexo, a diferença nas probabilidades de

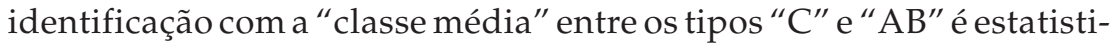
camente significativa ${ }^{32}$. Além disso, vemos, ainda na Tabela 7 que, para o tipo " $\mathrm{C}$ " - ao contrário do que acontece para o tipo " $\mathrm{AB}^{\text {" - }}$, as probabilidades de identificação com a "classe média" não são significativamente $^{33}$ superiores às probabilidades de identificação com a "classe média baixa" nem com a "classe trabalhadora".

A probabilidade de o tipo " $\mathrm{C}$ " identificar-se com a "classe média" é de 0,35 , e de 0,24 para identificar-se com a "classe média baixa"; no entanto, esse tipo também apresenta probabilidade de 0,23 e 0,15 de se identificar com a "classe trabalhadora" e com a "classe baixa/pobre", respectivamente.

Assim, o modelo utilizado nos informa que os indivíduos do tipo " $\mathrm{C}$ ", uma proxy do setor da população que nos últimos anos tem sido defini- 
do como a "nova classe média brasileira", não se percebem claramente como integrantes da "classe média" ou reivindicam pertencer a essa classe. Embora seja esta a identidade de classe mais provável para esse tipo, as outras identidades também estão muito presentes, inclusive a "classe baixa". Pode-se dizer, então, que não há uma identidade de classe muito clara para este perfil socioeconômico intermediário. So-

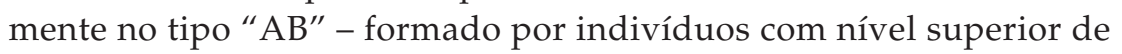
escolaridade, profissionais, administradores, com maiores chances de possuir plano de saúde, previdência privada, cujos filhos estudam em colégios particulares, e que frequentam teatros e fazem viagens internacionais - é que a identificação com a "classe média" se mostra nitidamente. $\mathrm{O}$ tipo " $\mathrm{AB}$ ", perfil mais abastado da população brasileira, é o único em que as pessoas se identificam de modo bastante claro com a "classe média".

Complementando nossa análise, com o objetivo de tornar mais palpável a consideração dos efeitos de cada uma das principais variáveis independentes sobre as probabilidades de identificação com a classe média, o Gráfico 4 traz algumas outras simulações com as probabilidades preditas, as quais nos ajudam a entender os efeitos das variáveis socioeconômicas (ocupação, escolaridade e renda) sobre a probabilidade de identificação com a "classe média".

O gráfico mostra as variações na probabilidade de os indivíduos adotarem uma identidade de "classe média" de acordo com seu nível de escolaridade (até 4 anos de estudo; de 5 a 8 anos; de 9 a 11 anos; 12 anos ou mais), categoria ocupacional (trabalhadores rurais; manuais não qualificados; manuais qualificados; não manuais de rotina e profissionais e administradores) e nível de renda (E, D, C e AB) - que são as variáveis socioeconômicas que mais contribuem para o poder explicativo do modelo ${ }^{34}$.

No conjunto de gráficos acima, cada quadro representa um nível educacional, e dentro de cada quadro, da esquerda para a direita, temos os níveis de renda (do " $\mathrm{E}$ " para o " $\mathrm{AB}$ "). Além disso, cada linha nos gráficos representa uma categoria ocupacional. Consequentemente, o espaço entre linhas representa os "efeitos da categoria ocupacional", a inclinação das retas representa o "efeito da renda", e as diferenças entre os quadros representa o "efeito da escolaridade".

Conforme esperado, verificamos uma inclinação positiva a partir do nível de renda " $\mathrm{E}$ " até o nível " $\mathrm{AB}$ " para todas as linhas em todos os

DADOS - Revista de Ciências Sociais, Rio de Janeiro, vol. 58, nº 1, 2015 


\section{Gráfico 4}

Modelo Logit Multinomial para Identidades de Classe: Probabilidades Preditas para "Classe Média", por Tipos Socioeconômicos

(Brasil, 2008) (\%)

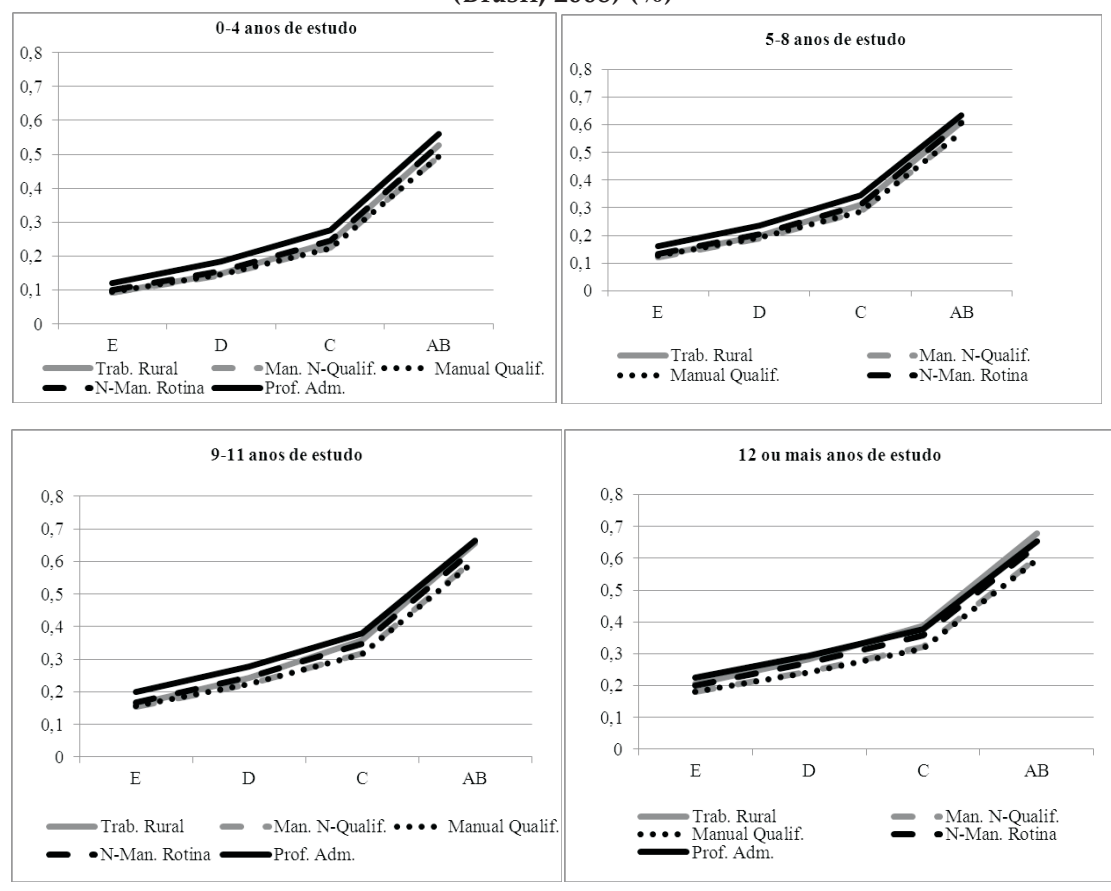

Fonte: Pesquisa sobre a Classe Média 2008 (Banco de Dados, Cesop/Unicamp). Disponível em: http://www.cesop.unicamp.br/site/htm/busca/php. Acessado em 5/6/2012.

Tabulação do próprio autor.

quadros, o que representa visualmente o efeito positivo dos rendimentos sobre a probabilidade de identificação com a "classe média". Além disso, vemos que o efeito da renda sobre essas probabilidades é maior que o efeito da escolaridade ou da ocupação; isso é verdade especialmente pela inclinação mais acentuada que verificamos entre os intervalos de renda " $\mathrm{C}$ " $\mathrm{e}$ " $\mathrm{AB}$ ".

É possível verificar que, apesar de uma inclinação quase constante do nível " $\mathrm{E}$ " até $\mathrm{o}$ " $\mathrm{C}$ ", há um aumento bastante acentuado da inclinação entre o nível "C" e o "AB". Isso significa que esse último intervalo de renda, que agrega os indivíduos e famílias mais abastados do país, possui probabilidades muito maiores que os demais de identificação com a "classe média" - controlando pelos efeitos de outras variáveis, inclusive o grau de escolaridade e a categoria ocupacional, conforme exposto no Gráfico 4. 
Essas observações nos permitem tirar duas conclusões. A primeira é que os indivíduos situados em posições superiores (perfil "AB") são os que possuem probabilidades mais altas de se identificarem com a "classe média" no Brasil; enquanto os que ocupam posição intermediária - e que vêm sendo denominados "nova classe média" - não apresentam identificação muito clara com nenhuma classe. Em segundo lugar, nosso modelo também mostrou que a principal influência sobre a probabilidade de identificação com a classe média provém da renda - mesmo quando comparada com escolaridade, consumo e ocupação -, e que alcançar o nível " $A B$ " de rendimentos se mostra extremamente relevante para que o indivíduo se perceba como integrante da classe média.

As análises apresentadas neste trabalho indicam que os indivíduos que nos últimos anos têm sido reconhecidos como "a nova classe média brasileira" - ou o agregado de renda " $C$ " - não possuem uma clara identidade de classe. Ao contrário, vimos que somente entre os indiví-

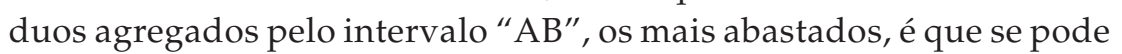
encontrar uma predominância da identidade de "classe média".

\section{O QUE É NECESSÁRIO PARA FAZER PARTE DA CLASSE MÉDIA NO BRASIL?}

Conforme comentamos anteriormente, o chamado processo de identificação poderia ser dividido em dois momentos, interno e externo, correspondentes à autoidentificação e à classificação externa. Apesar de empiricamente não ser possível separá-los de todo, trata-se na verdade de uma importante distinção analítica, já que, por exemplo, identificar-se como pertencendo à classe média não significa, necessariamente, ser aceito ou reconhecido por terceiros enquanto tal. Por essa razão, consideramos importante tratar, também, da percepção dos brasileiros sobre esta classe, verificando o que eles acreditam ser necessário para ser reconhecido como parte dela ${ }^{35}$.

No "survey sobre a classe média brasileira", pediu-se aos entrevistados que declarassem em que medida ("essencial", "muito importante", "mais ou menos importante", ou "nada importante") eles acreditavam que, para fazer parte da classe média, seria importante possuir os seguintes atributos: ter nível superior de escolaridade; ter uma ocupação de prestígio; possuir rendimentos altos; ter casa própria; ser dono do 
próprio negócio; ter acesso a lazer e diversão; possuir um padrão de vida estável; e ter acesso a escolas/universidades privadas.

O Gráfico 5 apresenta a porcentagem de pessoas que disseram ser "essencial" ou "muito importante" possuir cada uma das características citadas:

Podemos verificar que todas as características mencionadas são altamente valorizadas. Aquela que apresentou a menor porcentagem de respostas positivas foi "possuir seu próprio negócio", com aproximadamente $70 \%$ dos entrevistados afirmando ser este um fator "essencial" ou "muito importante" para ser da classe média. Por outro lado, "possuir um padrão de vida estável" foi a característica mais valorizada, com quase $95 \%$ de respostas positivas. Ela é, então, seguida por "casa própria", "acesso a lazer e diversão", "renda alta", "acesso a educação particular" e, finalmente, "negócio próprio".

\section{Gráfico 5}

Características Importantes para se Fazer Parte da Classe Média: Porcentagem Afirmando que é "Essencial" ou "Muito Importante" (Brasil, 2008)

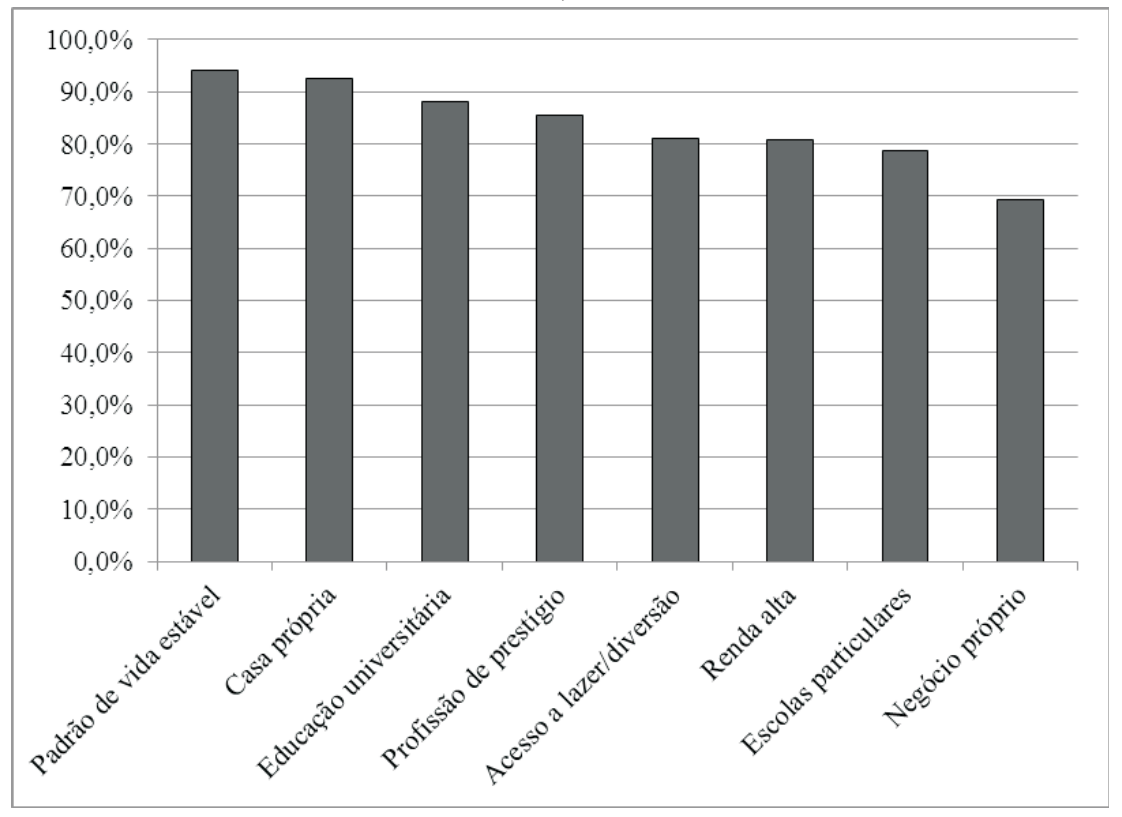

Fonte: Pesquisa sobre a Classe Média 2008 (Banco de Dados, Cesop/Unicamp). Disponível em: http://www.cesop.unicamp.br/site/htm/busca/php. Acessado em 5/6/2012. Tabulação do próprio autor. 
Assim, no Brasil, a imagem do que é fazer parte da classe média envolve, em grande medida, possuir um padrão de vida estável, ter feito universidade, ter renda alta, ter acesso a lazer e diversão etc. Como vimos, essas são características que dificilmente se encaixam no perfil do brasileiro "mediano"; ao contrário, trata-se de uma imagem que é muito mais próxima da camada mais abastada, de perfil " $\mathrm{AB}^{\text {". }}$

Mas, talvez, o fato mais surpreendente é que parece haver uma espécie de consenso, que atravessa as camadas sociais, a respeito da importância de diferentes fatores que caracterizam o integrante da classe média. O Gráfico 6 corrobora esse argumento ao mostrar as porcentagens de avaliações positivas ("essencial" ou "muito importante") entre os diferentes níveis de renda e escolaridade:

Pode-se ver que, com algumas exceções, a porcentagem de avaliações positivas para cada uma das características é alta e similar em todos os níveis de escolaridade e rendimentos. De qualquer maneira, algumas variações devem ser consideradas. Por exemplo, enquanto somente

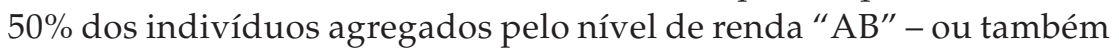
pelo nível "superior" de escolaridade (12 anos ou mais) - acreditam que "negócio próprio" é uma importante característica para se fazer parte da classe média, entre os indivíduos agregados pelo nível "E" de renda - ou também com baixa escolaridade - esse percentual chega a quase $80 \%$. Um padrão similar, embora menos acentuado, ocorre no

Gráfico 6

Características Importantes para se Fazer Parte da Classe Média: Porcentagem Afirmando que é "Essencial" ou "Muito Importante", por Níveis de Renda e Anos de Estudo (Brasil, 2008) (\%)

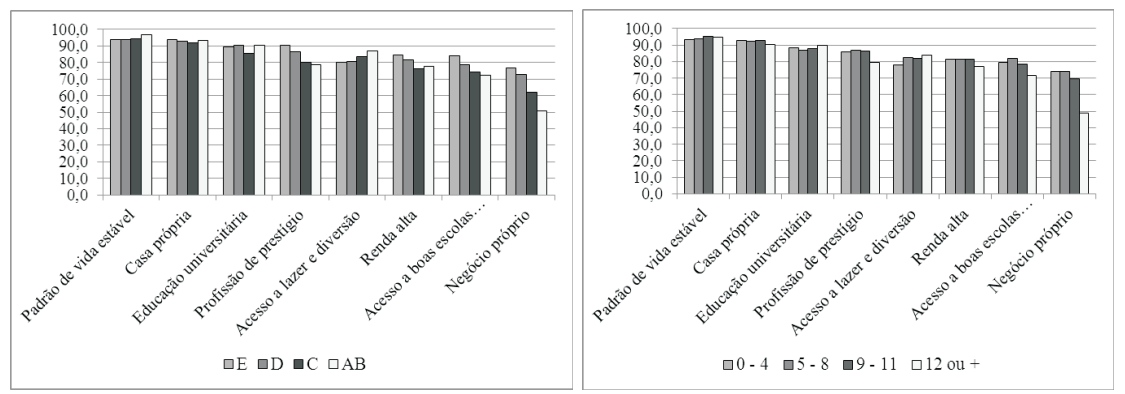

Fonte: Pesquisa sobre a Classe Média 2008 (Banco de Dados, Cesop/Unicamp). Disponível em: http://www.cesop.unicamp.br/site/htm/busca/php. Acessado em 5/6/2012. Tabulação do próprio autor.

DADOS - Revista de Ciências Sociais, Rio de Janeiro, vol. 58, nº 1, 2015 
que se refere a "renda alta" e "educação privada", com porcentagens menores para o nível "AB" de renda ou "superior" de escolaridade. Por outro lado, níveis mais elevados de rendimentos e educação tendem a apresentar percentuais mais altos de avaliação positiva em relação a características como "padrão de vida estável" e "acesso a lazer e diversão".

Assim, se por um lado parece haver um consenso entre os diversos níveis socioeconômicos de que as características mencionadas seriam todas importantes para uma pessoa ser considerada de classe média, por outro, os indivíduos de nível socioeconômico mais elevado apresentam uma tendência um pouco maior a negar a importância de características como "ocupação de prestígio", "negócio próprio" e "renda alta", e a atribuir maior importância a fatores como "padrão de vida estável" e "acesso a lazer e diversão".

Uma vez mais devemos lembrar, no entanto, que o fato mais marcante é que a grande maioria dos brasileiros, independentemente de seu nível socioeconômico, tende a considerar as características analisadas como muito importantes ou essenciais para uma pessoa fazer parte da classe média. Isso é ainda mais surpreendente quando levamos em conta a natureza das características avaliadas, que incluem renda alta, nível superior de escolaridade, ocupação de prestígio, acesso a lazer e diversão, padrão de vida estável etc. Consequentemente, quando são estimulados a revelar suas identidades de classe, esses indivíduos têm em mente a imagem de uma classe média que dificilmente corresponde ao perfil do brasileiro mediano. Isso nos ajuda a compreender por que somente entre as camadas mais abastadas a proporção de pessoas que se identificam como de classe média se destaca.

Dessa maneira, os dados apresentados nesta seção evidenciam que a ideia de classe média no Brasil não parece corresponder às características dos setores intermediários - intervalo de renda " $C$ " - da população brasileira. Ao contrário, ela se encontra muito mais próxima do perfil "AB", de indivíduos e famílias mais abastados. Nesse sentido, parece pouco provável que aqueles milhões de pessoas que nos últimos anos alcançaram níveis intermediários de rendimento possam vir a ser reconhecidos como membros da classe média brasileira.

\section{CONCLUSÕES}

Neste artigo tratamos de uma questão central para a compreensão das mudanças pelas quais a sociedade brasileira passou nos últimos anos: 
o surgimento do que vem sendo denominado de "nova classe média brasileira". Trata-se, como vimos, da ampliação daquela camada estatisticamente intermediária da população em termos socioeconômicos, e cuja participação no seio da população brasileira ultrapassou os $50 \%$ no ano de 2008. Por esta razão, foi feita a afirmação de que o Brasil havia se tornado um país de classe média.

Essa declaração foi o estopim de um enorme debate, no qual se travaram disputas a respeito da interpretação desses movimentos recentes na estratificação social, havendo basicamente duas posições contrárias: a primeira, mais próxima dos estudos econômicos, e que tomava esta camada estatisticamente intermediária como proxy da classe média brasileira; e a segunda, que discordava dessa interpretação ao lembrar da importância de outros fatores além da renda, como categorias ocupacionais e/ ou capital cultural, para o estudo e definição das classes. Assim, segundo esta última perspectiva, não seria correto identificarmos essa camada intermediária e seus integrantes como classe média, tendo em vista que eles careceriam seja de uma posição ocupacional-estrutural, seja do aporte de capital cultural, supostamente "típicos" dessa classe.

Em trabalhos anteriormente publicados, argumentamos que a análise de classes feita através de categorias sócio-ocupacionais mostrava que a estrutura de desigualdades da sociedade brasileira não teria passado por transformações substantivas nos últimos anos, lançando dúvidas então sobre a tese da "nova classe média" (Scalon e Salata, 2012). No entanto, se por um lado é verdade que as informações ocupacionais, e também aquelas relativas ao capital cultural, nos permitiam uma análise e compreensão mais profundas da estrutura de desigualdades e de sua reprodução, quando comparadas com os estudos que focam somente em informações de rendimentos, por outro, percebíamos que esse tipo de análise também não conseguia dar resposta a importantes questões: esses indivíduos, a agora famosa "classe C", se reconheceriam como integrantes da classe média? Seriam eles considerados por outros indivíduos como parte dessa classe? Afinal, qual estrato no Brasil tipicamente se identificaria, e seria identificado, com a classe média? Essas questões, que, a nosso ver, assinalam pontos essenciais deste debate, não podiam ser respondidas somente com as informações de renda, escolaridade ou ocupação.

Não se trata, como vimos, de um problema novo na bibliografia, muito pelo contrário. A definição dos contornos da classe média tem sido 
uma das tarefas mais desafiadoras da sociologia. Assim, em vez de adotarmos uma definição teórica, dada a priori, para então verificarmos se aquela crescente camada intermediária poderia ou não ser considerada como a classe média brasileira, decidimos nos dedicar à análise de como os próprios indivíduos se percebem, identificando-se ou não com essa classe.

Ao seguir este caminho, nos inserimos em um importante movimento que tem ocorrido dentro dos estudos internacionais a respeito das desigualdades e classes sociais. Tendo sido por alguns anos relegada a segundo plano, a esfera subjetiva da estratificação foi retomada como aspecto central dos estudos de classe (Devine e Savage, 2005), conforme procuramos evidenciar nas primeiras seções deste artigo.

Os resultados por nós alcançados mostram que a classe média no Brasil diz respeito não àquela camada estatisticamente intermediária - a “classe C" de Neri (2008) -, mas sim aos indivíduos mais abastados (camada " $A B^{\prime \prime}$ ) da população: pessoas com renda domiciliar elevada, nível superior de escolaridade, inseridas em categorias ocupacionais de prestígio médio-alto, com maiores probabilidades de possuir plano de saúde, poupança, frequentar teatros, viajar para o exterior, ter os filhos estudando em escolas privadas etc. São essas pessoas que formam a classe média brasileira, embora estejam longe de ser a imagem mais próxima do brasileiro mediano, ou a camada intermediária.

Além disso, foi também possível verificar, através de nossa análise, que a renda é a variável mais importante para a identificação com a classe média, quando comparada com escolaridade, ocupação etc. Atingir um nível " $A B$ " de rendimentos se mostra como condição fundamental para a identificação com a classe média, mesmo quando mantemos constantes as outras variáveis independentes.

A fim de aprofundar nossa análise, no decorrer deste artigo tomamos como objeto não somente as identidades de classe, mas, também, as percepções dos indivíduos sobre o que os mesmos consideram ser necessário para fazer parte da classe média. Como resultado, vimos que parece haver um consenso, que percorre os vários estratos sociais, acerca da importância de algumas características que uma pessoa deve ter a fim de fazer parte da classe média no Brasil; e isso é ainda mais surpreendente quando levamos em conta a natureza das características avaliadas, que incluem renda alta, nível superior de escolaridade, ocupação de prestígio, acesso a lazer e diversão, padrão de vida estável 
etc. Essas são características que, com algumas ressalvas, poderiam facilmente ser compartilhadas pelos indivíduos e famílias provenientes das camadas mais abastadas da sociedade brasileira (perfil AB), mas dificilmente corresponderiam à realidade daqueles que estão situados em posições intermediárias, ou seja, a chamada "classe média estatística" (Neri, 2008).

Esses resultados corroboram os argumentos levantados pela literatura sociológica mais recente sobre a classe média brasileira (O'Dougherty, 2002; Owensby, 1999). Tais autores, como vimos, afirmam que a ideia de classe média no Brasil teria sido formada tendo como referência a imagem - um tanto idealizada - da classe média europeia e norteamericana. Isso significa que, conforme verificado em nossas análises empíricas, apenas os setores mais abastados da população brasileira seriam capazes de corresponder àquele ideal. Dessa maneira, a análise aqui empreendida corrobora nossa hipótese, mostrando que no Brasil a classe média - ao menos na condição de uma coletividade com a qual os indivíduos se identificam, e são identificados - não corresponde às características dos setores intermediários (intervalo de renda " $\mathrm{C}$ ") da população brasileira; ao contrário, ela estaria muito mais próxima do perfil " $A B$ ", dos indivíduos e famílias mais abastados.

Deve-se ter em vista, portanto, que dada a posição periférica de países como o Brasil, a ideia de "classe média" surgiu nos chamados países centrais, e foi posteriormente absorvida pela sociedade brasileira no contexto específico de meados do século XX. Conforme argumentado por autores como Owensby (1999), numa situação em que os países centrais eram vistos como ápice do desenvolvimento em direção ao qual, acreditava-se, o Brasil estava começando a caminhar, ser reconhecido como pertencente à "classe média" significava ser reconhecido como parte desse mundo "desenvolvido". Significava, portanto, uma posição social superior, que deveria corresponder a certo grau de prestígio ou status social. Afirmava-se, dessa maneira, aquilo que Souza (2003) identificara como a separação simbólica entre "europeizados" e "não europeizados"; e se reconhecer e ser reconhecido como membro da "classe média" significa(va) também fazer parte da primeira categoria.

Conforme procuramos argumentar anteriormente, baseando-nos na bibliografia recente sobre o tema, as identidades de classe devem ser tomadas não como percepções corretas ou equivocadas de uma dada

DADOS - Revista de Ciências Sociais, Rio de Janeiro, vol. 58, nº 1, 2015 
posição objetiva definida a priori, mas como reivindicações de pertencimento que participam ativamente na própria formação, manutenção e questionamento dos contornos das classes e hierarquias sociais. Com efeito, os resultados por nós alcançados, mostrando que somente a camada mais abastada da população possui uma identificação bastante clara e profunda com a classe média no Brasil, indicam que, ao menos enquanto um grupo socialmente significativo (ou uma formação social), a classe média brasileira seria composta pelos setores mais abastados ("AB") da população, e não pelos setores intermediários ("C"). Nesse sentido, não haveria uma coincidência entre a "classe média estatística" de Neri (2008) e a formação de classe média no Brasil.

Apoiada no discurso oficial, a tese da "nova classe média brasileira" ganhou força nos meios de comunicação de massa e no debate público de uma maneira geral. No entanto, conforme verificamos no presente trabalho, há uma aparente desconexão entre a denominação que vem sendo utilizada e as percepções dos brasileiros em geral e, mais especificamente, dos indivíduos que fazem parte da camada intermediária de renda. Dada essa discrepância entre parte do discurso acadêmico (e oficial) e as percepções dos indivíduos, acreditamos ser pouco provável que, nos próximos anos, esse contingente de indivíduos "estatisticamente intermediários" venha a ser incorporado à formação de classe média.

Esperamos, assim, que as análises e resultados apresentados neste artigo, ao ressaltarem a esfera subjetiva da estratificação, possam trazer uma importante contribuição para o debate em curso sobre a classe média no Brasil.

(Recebido para publicação em agosto de 2013)

(Reapresentado em maio de 2014)

(Aprovado para publicação em outubro de 2014) 


\section{NOTAS}

1. O estudo coordenado por Neri (2008) baseia-se no chamado "Critério Brasil" e divide a sociedade brasileira em quatro faixas de renda (AB, C, D e E). Da faixa E fazem parte aqueles com renda (preços de 2008) de até $R \$ 768,00$ (limite calculado tendo como base a linha de miséria); entre $\mathrm{R} \$ 768,00$ e $\mathrm{R} \$ 1.064,00$ (calculado com base na mediana da distribuição) estão aqueles que fazem parte da faixa D; a chamada nova classe média, faixa $C$, é composta pelos que têm renda entre $R$ \$ 1.064,00 e $R$ \$ 4.591,00 (nono decil da distribuição); por fim, fazem parte da elite nacional, faixa $\mathrm{AB}$, aqueles com renda de, no mínimo, $\mathrm{R} \$ 4.591,00$.

2. Referência também deve ser feita ao papel exercido pela expansão do crédito.

3. Ver a Tabela 1, em anexo.

4. Sobre esse debate, ver Crompton (2010), Goldthorpe (2009) e Wright (2005).

5. A questão das identidades de classe, ou seu suposto enfraquecimento nos países desenvolvidos, tem inclusive ocupado uma posição central no atual debate a respeito da pertinência das análises de classe (Savage et al., 2001). Autores como Bauman (1999); Giddens (1990); Beck (1992); Lash e Urry $(1987,1994)$, por exemplo, argumentam que o suposto arrefecimento das identidades de classe seria forte indicação de uma mudança societária e cultural que nos teria levado para além do paradigma da sociedade industrial com divisões de classe. Alegam, assim, com base na questão subjetiva - das identidades-, que os já tradicionais estudos de classe não fariam mais sentido na sociedade contemporânea.

6. Para uma revisão desta bibliografia, ver Devine e Savage (2005).

7. Parte da literatura sobre o tema tem, inclusive, preferido utilizar o termo "identificação" em vez de "identidade", a fim de fazer alusão à ideia de um processo contínuo.

8. Para um contraponto a esse respeito, ver Brubaker e Cooper (2000).

9. Apesar de se constituir em uma importante separação analítica, na realidade esses dois momentos do processo de identificação (autodefinição e categorização) estariam fortemente relacionados, sendo quase sempre impossível afirmar a precedência de um sobre o outro, ou analisá-los separadamente.

10. Bourdieu $(1979,1984,1987,1988,2008)$ denominou este processo de "lutas classificatórias".

11. Para uma discussão mais aprofundada, ver Jenkins (1996).

12. Para uma revisão da literatura sobre classe média no Brasil, ver Pochman et al. (2006).

13. Para maiores detalhes, consultar Souza e Lamounier (2010).

14. Dado o caráter não probabilístico (por cotas) do último estágio de seleção da amostra, as inferências estatísticas, e/ ou os testes de hipóteses, a serem apresentados, devem ser considerados com muita cautela.

15. Todos os valores dizem respeito à renda domiciliar total, em preços de agosto de 2008.

16. Devido a certas limitações da base de dados, no entanto, não foi possível construir todas as categorias presentes no esquema EGP.

17. Que não necessariamente coincidia com os indivíduos entrevistados.

18. Além de "inativos/desempregados".

DADOS - Revista de Ciências Sociais, Rio de Janeiro, vol. 58, nº 1, 2015 


\section{André Ricardo Salata}

19. Não temos aqui a intenção de fazer um estudo elaborado a respeito de padrões de consumo e/ou estilos de vida, mas somente oferecer um complemento à análise da relação entre tipo socioeconômico e identidades de classe.

20. K-means cluster.

21. O principal objetivo da Análise de Correspondência é revelar a estrutura de dados volumosos de uma matriz substituindo-os por uma representação mais simples sem perder informações essenciais. Além disso, a Análise de Correspondência também torna possível representar os resultados visualmente, como pontos dentro de um espaço formado pelos eixos principais extraídos dos dados, facilitando, assim, sua interpretação. Resumidamente, categorias com distribuições similares serão representadas por pontos que estarão próximos nesse espaço, enquanto categorias que possuem uma distribuição muito desigual estarão representadas por pontos mais afastados naquele mesmo espaço (Clausen, 1988; Le Roux e Rouanet, 2010).

22. Como as distâncias "qui-quadradas" utilizam as proporções marginais no denominador, categorias com frequências muito baixas tendem a ganhar uma ênfase indevida neste tipo de análise (Greenacre, 2010). Assim, devido ao pequeno número de casos (30) na identidade de "classe média alta", agregamos essa categoria à de "classe média". O único caso de identidade de "classe alta", por sua vez, foi retirado da análise. Portanto, quando nos referimos à identidade de "classe média" é importante notar, para fins de interpretação, que esta inclui também os poucos casos de "classe média alta".

23. Para uma exposição detalhada sobre esta técnica, ver Powers e Xie (2008).

24. Infelizmente, a base de dados com que estamos trabalhando não traz informações sobre "cor". No entanto, fizemos alguns testes com outro banco de dados sobre desigualdades, referente ao programa ISSP, aplicado para uma amostra também representativa da população brasileira no ano de 1999. Essa base trazia, além das variáveis sobre identidades de classe, informações como rendimentos, escolaridade, idade e também sobre uma variável de "cor". Assim, rodamos um modelo similar ao que estamos usando aqui, mas incluindo essa última variável, de modo a testar a hipótese de que a "cor" exerce influência sobre as identidades de classe. Verificamos que o fato de o indivíduo não ser "branco" diminuía suas chances de identificação com a classe média - ao invés da classe baixa / pobre - apenas quando não incluíamos as outras variáveis socioeconômicas (como renda, escolaridade e prestígio ocupacional). Quando estas últimas eram incluídas no modelo, o efeito da "cor" passava a não ser mais significativo. Nesse sentido, temos bases suficientemente fortes para acreditar que a ausência dessa variável em nosso modelo não provocará fortes dúvidas sobre nossos resultados.

25. Rodamos também os dois testes mais comuns para o pressuposto da "Independência das Alternativas Irrelevantes" (IIA): o "Hausman-McFadden test" (Hausman e McFadden, 1984) e o "Small-Hsiao test" (Small e Hsiao, 1985). Como se pode verificar nas Tabelas 4 e 5 em anexo, ambos os testes mostram que nosso modelo não viola esse pressuposto, indicando que é apropriado utilizarmos o modelo multinomial.

26. Já que é aquela com maior número de casos.

27. Os municípios onde os indivíduos entrevistados moravam foram classificados em: capitais (capitais de cada estado da Federação), periferia (municípios que integravam a periferia das principais regiões metropolitanas do país: Belém, Fortaleza, Re- 
cife, Salvador, Belo Horizonte, Rio de Janeiro, São Paulo, Curitiba e Porto Alegre), e interior (municípios que não eram capitais nem integravam a periferia das principais metrópoles).

28. Sabe-se que modelos logísticos produzem estimações enviesadas quando lidamos com categorias raras (King e Langche, 2001). Mais uma vez, então, devido ao pequeno número de casos (30) na identidade de "classe média alta", juntamos essa categoria com a "classe média"; o único caso de identidade de "classe alta", por sua vez, foi retirado da análise.

29. Poderia ser argumentado que, em lugar de um modelo multinomial, seria melhor fazer uso de um modelo ordinal, já que permitiria identificar uma ordem nas categorias de nossa variável dependente. No entanto, conforme afirmado por Powers e Xie (2008), essa escolha depende dos objetivos da pesquisa. Já que nosso interesse aqui é avaliar as diferenças em termos de identidade de classe e os efeitos de variáveis independentes sobre essas identidades - especialmente sobre a categoria "classe média" -, resolvemos utilizar modelos logit multinomiais. De todo modo, é importante lembrar, que o teste estatístico das linhas paralelas rejeitara - no nível de 0,001 - o pressuposto da regressão ordinal de que os parâmetros são constantes através das categorias de resposta (Long e Freese, 2006).

30. Valores imputados com base nas médias ou modas das respectivas variáveis.

31. A Tabela 6 em anexo traz os intervalos de confiança (95\%) para essas probabilidades preditas; e a Tabela 7, também em anexo, traz os intervalos de confiança (95\%) para as variações de probabilidades (entre um tipo e outro), testando se estas diferenças seriam estatisticamente significativas ou não.

32. Já que o intervalo de confiança ( $95 \%$ ) não inclui o valor zero (“0”).

33. Ao nível de $95 \%$.

34. As demais variáveis foram fixadas nos seguintes valores: homens, 35 anos de idade, região Sudeste, capital e consumo intermediário.

35. É importante lembrar, entretanto, que a autoidentificação provavelmente já é muito influenciada pelas classificações externas, sendo impossível separá-las por completo no plano empírico. 


\section{REFERÊNCIAS BIBLIOGRÁFICAS}

BARROS, Ricardo et al. (2010), “Determinantes da Queda na Desigualdade de Renda no Brasil". Texto para Discussão, no 1460. Brasília, Ipea.

BAUMAN, Zygmunt. (1999), Memories of Class (Routledge Revivals): The Pre-history and After-life of Class. London, Routledge.

BECK, Ulrich. (1992), Risk Society: Towards a New Modernity (vol.17). London, Sage.

BOURDIEU, Pierre. (1979), La Distinction: Critique Sociale du Jugement. Paris, Éditions de Minuit.

. (1984), "Social Space and the Genesis of Groups". Theory and Society, no 14, pp. 723-744.

. (1987), "What Makes a Social Class? On the Theoretical and Practical Existence of Groups”. Berkeley Journal of Sociology, no 32, pp. 1-18.

. (1988), "Social Space and Symbolic Power". Sociological Theory, no 7, pp. 14-25.

. (2008), A Distinção: Crítica Social do Julgamento. São Paulo, Edusp.

BRADLEY, Harriet. (1996), Fractured Identities: Changing Patterns of Inequality. Cambridge, Polity Press.

BRUBAKER, Rogers e COOPER, Frederick. (2000), "Beyond 'Identity'”. Theory and Society, vol. 29, no 1, pp. 1-47.

BUTLER, Tim e SAVAGE, Mike (eds.). (1995), Social Change and the Middle Classes. London, Routledge.

CHARLESWORTH, Simon J. (2000), A Phenomenology of Working-Class Experience. Cambridge, Cambridge University Press.

CLAUSEN, Sten-Erik. (1988), Applied Correspondence Analysis: An Introduction. Thousand Oaks, CA, Sage (Sage University Paper Series on Quantitative Applications in the Social Sciences).

CROMPTON, Rosemary. (2010), "Class and Employment". Work, Employment and Society, vol. 24, no 1, pp. 9-26.

DEVINE, Fiona. (1992), "Social Identities, Class Identities and Political Perspectives". Sociological Review, no 40, pp. 229-252.

_ e SAVAGE, Mike. (2005), “The Cultural Turn, Sociology and Class Analysis”, in F. Devine et al. (orgs.), Rethinking Class: Culture, Identities and Lifestyles. New York, Palgrave Macmillan.

DEVINE, Fiona et al. (2005), Rethinking Class: Culture, Identities and Lifestyles. New York, Palgrave Macmillan.

EIJK, Gwen. (2012), “Hostile to Hierarchy? Individuality, Equality and Moral Boundaries in Dutch Class Talk". Sociology, vol. 47, no 3, pp. 526-541.

ERIKSON, Robert; GOLDTHORPE, John H. e PORTOCARERO, Lucienne. (1979), "Intergenerational Class Mobility in Three Western European Societies". British Journal of Sociology, no 30, pp. 415-441. 
FERNANDES, Florestan. (1975), Capitalismo Dependente e Classes Sociais na América Latina (2a ed.). Rio de Janeiro, Zahar Editora.

GANZEBOOM, Harry B. G. e TREIMAN, Donald J. (1996), “Internationally Comparable Measures of Occupational Status for the 1988 International Standard Classification of Occupations". Social Science Research, vol. 25, no 3, pp. 201-239.

GIDDENS, Anthony. (1990), The Consequences of Modernity. Cambridge, Polity Press.

GOLDTHORPE, John H. (2009), “Analyzing Social Inequality: A Critique of Two Recent Contributions from Economics and Epidemiology". European Sociological Review, vol. 26, no 6, pp. 731-744.

GREENACRE, Michael. (2010), Correspondence Analysis in Practice. London, Chapman and Hall/CRC.

HAUSMAN, Jerry e MCFADDEN, Daniel. (1984), “Specification Tests for the Multinomial Logit Model". Econometrica, no 52, pp. 1219-1240.

JENKINS, Richard. (1996), Social Identity. London, Routledge.

KING, Gary e LANGCHE, Zeng. (2001), "Logistic Regression in Rare Events Data”. Political Analysis, vol. 9, no 2, pp. 137-163.

LAMMONT, Michèle. (1992), Money, Moral e Manners: The Culture of the French and the American Upper-middle Class. Chicago, The University of Chicago Press.

LASH, Scott e URRY, John. (1987), The End of Organized Capitalism. Madison, University of Wisconsin Press.

. (1994), Economies of Signs and Space. London, Sage.

LE ROUX, Brigitte e ROUANET, Henry. (2010), Multiple Correspondence Analysis. London, Sage (Sage University Paper Series on Quantitative Applications in the Social Sciences, vol. 163).

LONG, J. Scott e FREESE, Jeremy. (2006), Regression Models for Categorical Dependent Variables Using Stata (2a ed.). College Station, Stata Press.

NERI, Marcelo. (2008), A Nova Classe Média. Rio de Janeiro, Centro de Políticas Sociais /FGV Editora.

O'DOUGHERTY, Maureen. (2002), Middle Classes, Ltd.: Consumption and Class Identity during Brazil's Inflation Crisis. Durham, Duke University Press.

OWENSBY, Brian P. (1999), Intimate Ironies: Modernity and the Making of the New Middle Class Lives in Brazil. Stanford, Stanford University Press.

POCHMANN, Marcio. (2012), Nova Classe Média? O Trabalho na Base da Pirâmide Social Brasileira. São Paulo, Boitempo.

_et al. (2006), Classe Média: Desenvolvimento e Crise. São Paulo, Cortez.

POWERS, Daniel e XIE, Yu. (2008), Statistical Methods for Categorical Data Analyses (2a ed.). Bingley, Emerald.

REAY, Diane. (2005), "Beyond Consciousness? The Psychic Landscape of Social Class". Sociology, vol. 39, no 5, pp. 911-928.

DADOS - Revista de Ciências Sociais, Rio de Janeiro, vol. 58, n 1, 2015 


\section{André Ricardo Salata}

SALATA, André. (2012), "A Nova Classe Média Brasileira: Contribuição para um Debate Político". Disponível em http://www.observatoriodasmetropoles.net/download/ texto_andre_salata_classe_media.pdf. Acessado em 5/5/2012.

SAVAGE, Mike; BAGNALL, Gaynor e LONGHURST, Brian. (2001), “Ordinary, Ambivalent and Defensive: Class Identities in the Northwest of England". Sociology, vol. 35, no 4, pp. 875-892.

SAYER, Andrew. (2005), “Class, Moral Worth and Recognition”. Sociology, vol. 39, no 5, pp. 947-963.

SCALON, Celi e SALATA, André. (2012), “Uma Nova Classe Média no Brasil da Última Década? O Debate a Partir da Perspectiva Sociológica". Sociedade e Estado, vol. 27, no 2, pp. 387-407.

SCOTT, John. (1996), Stratification and Power: Structures of Class, Status and Command. Cambridge, Polity Press.

SKEGGS, Beverley. (1997), Formations of Class and Gender. London, Sage.

SMALL, Kenneth A. e HSIAO, Cheng. (1985), "Multinomial Logit Specification Tests". International Economic Review, no 26, pp. 619-627.

SOBRINHO, Guilherme G. F. Xavier. (2011), “'Classe C' e sua Alardeada Ascensão: Nova? Classe? Média?". Indicadores Econômicos FEE, vol. 38, no 4, pp. 67-80.

SOUZA, Amaury e LAMOUNIER, Bolívar. (2010), A Classe Média Brasileira: Ambições, Valores e Projetos de Sociedade. Rio de Janeiro, Elsevier.

SOUZA, Jessé. (2003), A Construção Social da Subcidadania: Para uma Sociologia Política da Modernidade Periférica. Belo Horizonte, UFMG Editora.

. (2010), Os Batalhadores Brasileiros. Nova Classe Média ou Nova Classe Trabalhadora? Belo Horizonte, UFMG Editora.

WACQUANT, Loïc. (1992), “Making Class: The Middle Class(es) in Social Theory and Social Structure", in S. G. McNall, R. Levine e R. Fantasia (eds.), Bringing Class Back. Boulder, Westview Press, pp. 39-64.

WRIGHT, Erik Olin. (2005), Approaches to Class Analysis. Cambridge, Cambridge University Press. 


\section{ANEXO}

Tabela 1

Média de Renda, Escolaridade (anos) e ISEI* por Níveis de Renda** para Pessoas entre 15 e 50 Anos de Idade

(Brasil, 2009)

\begin{tabular}{l|c|c|c}
\hline \multirow{2}{*}{ Níveis de Renda } & $\begin{array}{c}\text { Renda Domiciliar } \\
\text { per capita }\end{array}$ & Anos de Escolaridade & ISEI \\
\cline { 2 - 4 } & Média & Média & Média \\
\hline E & 165,6 & 5,4 & 24,9 \\
D & 262,1 & 6,8 & 29,9 \\
C & 554,5 & 8,5 & 35,9 \\
AB & 2257,5 & 11,9 & 52 \\
\hline Total & $\mathbf{6 9 6 , 4}$ & $\mathbf{8 , 2}$ & 36,2 \\
\hline
\end{tabular}

Fonte: PNAD, 2009 / IBGE (tabulação própria).

*Standard International Socio-Economic Index of Occupational Status (Ganzeboom e Treiman, 1996).

**Renda domiciliar per capita de todos os trabalhos: $\mathrm{E}(\mathrm{R} \$ 00,00-\mathrm{R} \$ 140,00) ; \mathrm{D}(\mathrm{R} \$ 141,00-\mathrm{R} \$ 222,00)$;

$\mathrm{C}(\mathrm{R} \$ 223,00-\mathrm{R} \$ 964,00) ; \mathrm{AB}$ (mais de $\mathrm{R} \$ 965,00)$.

Tabela 2

Modelos Logit Multinomiais para Identidades de Classe

(Brasil, 2008)

\begin{tabular}{l|c|c|c|c}
\hline \multirow{2}{*}{ Características } & \multicolumn{3}{c}{ Modelos } \\
\cline { 3 - 5 } & Modelo 01 & Modelo 02 & Modelo 03 \\
\hline \multirow{2}{*}{ Descrição } & Var. Add & Intercepto & $\begin{array}{c}\text { Idade, gênero, re- } \\
\text { gião e localização }\end{array}$ & $\begin{array}{c}\text { Ocupação, escolarida- } \\
\text { de, renda e consumo }\end{array}$ \\
\cline { 2 - 5 } & Model X2 & 0 & 156,23 & 564,895 \\
\hline \multirow{3}{*}{-2LL Ratio Test } & df & 0 & 28 & 80 \\
& sig. & - & 0 & 0 \\
\hline \multirow{2}{*}{ Pseudo-R2 } & Cox e Snell & - & 0,082 & 0,265 \\
& Nagelkerke & - & 0,086 & 0,28 \\
\hline Predit. & McFadden & - & 0,029 & 0,103 \\
\hline
\end{tabular}

Fonte: Pesquisa sobre a Classe Média 2008 (Banco de Dados, Cesop/Unicamp). Disponível em: http://www.cesop.unicamp.br/site/htm/busca/php. Acessado em 5/6/2012. Tabulação do próprio autor. 
André Ricardo Salata

Tabela 3

Regressão Logit Multinomial para Identidades de Classe: Coeficientes (razões de chance) e Testes de Significância dos Mesmos (Brasil, 2008)

\begin{tabular}{|c|c|c|c|c|}
\hline \multirow{2}{*}{ Variáveis } & CM(ref: CB) & CMB(ref: CB) & CT(ref: CB) & $N($ ref: $C B)$ \\
\hline & $\operatorname{Exp}(b)$ & $\operatorname{Exp}(b)$ & $\operatorname{Exp}(b)$ & $\operatorname{Exp}(b)$ \\
\hline Anos de Idade & 1,004 & 1,007 & 0,995 & 0,991 \\
\hline Gênero: Masc. $(r e f=f e m)$ & 1,081 & 1,119 & 1,233 & 0,705 \\
\hline Reg1: N/CO (ref=Sul) & $0,644^{*}$ & 0,711 & 1,057 & $0,258^{* * *}$ \\
\hline Reg2: NE (ref=Sul) & 0,826 & 0,85 & $1,640^{* *}$ & $0,349^{* * *}$ \\
\hline Reg3: SE (ref=Sul) & 1,164 & 1,012 & 1,016 & 0,727 \\
\hline Loc1: Cap. (ref=int) & $0,685^{* *}$ & 1,065 & 1,323 & $0,361^{* * *}$ \\
\hline Loc2: Perf. (ref=int) & $0,622^{* *}$ & 0,923 & 0,934 & $0,367^{* *}$ \\
\hline Esc1: 0-4 (ref:=12+) & $0,251^{* * *}$ & $0,218^{* * *}$ & $0,519^{*}$ & 1,494 \\
\hline Esc2: 5-8 (ref:=12+) & $0,343^{* * *}$ & $0,235^{* * *}$ & $0,480^{* *}$ & 1,475 \\
\hline Esc3: 9-11 (ref:=12+) & $0,538^{* *}$ & $0,394^{* * *}$ & 0,634 & 1,152 \\
\hline Cons1: Baixo (ref=alto) & $0,543^{* * *}$ & $0,461^{* * *}$ & 0,902 & 0,558 \\
\hline Cons2: Interm. (ref=alto) & 0,773 & 0,734 & 1,35 & 0,521 \\
\hline Renda1: $\mathrm{E}(\mathrm{ref}=\mathrm{AB})$ & $0,052^{* * *}$ & $0,213^{* * *}$ & 0,437 & 0,627 \\
\hline Renda2: D (ref=AB) & $0,113^{* * *}$ & $0,387^{*}$ & 0,671 & 0,808 \\
\hline Renda3: $\mathrm{C}(\mathrm{ref}=\mathrm{AB})$ & $0,258^{* * *}$ & 0,747 & 0,924 & 0,696 \\
\hline $\begin{array}{l}\text { Class1: Apos./Desmp. } \\
\text { (ref=prof.adm) }\end{array}$ & 0,768 & 0,655 & $0,484^{* *}$ & 0,713 \\
\hline $\begin{array}{l}\text { Class2: Trab. Rural } \\
\text { (ref=prof.adm) }\end{array}$ & 0,635 & $0,362^{* *}$ & 0,977 & 0,521 \\
\hline $\begin{array}{l}\text { Class3: Manual N. Qualif. } \\
\text { (ref=prof.adm) }\end{array}$ & $0,634^{*}$ & 0,761 & 0,837 & $0,457^{* *}$ \\
\hline $\begin{array}{l}\text { Class4: Man. Qualif. } \\
\text { (ref=prof.adm) }\end{array}$ & 0,753 & 0,914 & 1,147 & $0,243^{* *}$ \\
\hline $\begin{array}{l}\text { Class5: N-Manual Rot. } \\
\text { (ref=prof.adm) }\end{array}$ & 0,659 & 0,64 & 0,792 & $0,278^{* *}$ \\
\hline
\end{tabular}

Fonte: Pesquisa sobre a Classe Média 2008 (Banco de Dados, Cesop/Unicamp). Disponível em http://www.cesop.unicamp.br/site/htm/busca/php. Acessado em 5/6/2012. Tabulação do próprio autor.

${ }^{*} \mathrm{p}<=0,1 ;{ }^{* *} \mathrm{p}<=0,05 ;{ }^{* * *} \mathrm{p}<=0,01$ 
Quem é Classe Média no Brasil? Um Estudo sobre Identidades de Classe

Tabela 4

Hausman-McFadden: Pressuposto da IIA

\begin{tabular}{l|c|c|c|c}
\hline Omitted & $\mathbf{c h i}^{\mathbf{2}}$ & $\mathbf{d f}$ & $\mathbf{P}>\mathbf{c h i}^{\mathbf{2}}$ & Evidence \\
\hline $\mathrm{CM}$ & $-10,758$ & 61 & - & - \\
$\mathrm{CMB}$ & 0,482 & 62 & 1 & for H0 \\
$\mathrm{CT}$ & $-10,904$ & 62 & - & - \\
$\mathrm{N}$ & 0,057 & 62 & 1 & for H0 \\
\hline
\end{tabular}

Fonte: Pesquisa sobre a Classe Média 2008 (Banco de Dados, Cesop/Unicamp). Disponível em: http:/ / www.cesop.unicamp.br/site/htm/busca/php. Acessado em 5/6/2012. Tabulação do próprio autor.

Nota: H0: Chances (Resultado-J em vez de Resultado-K) são independentes das demais alternativas.

Se $\mathrm{chi}^{2}<0$, o modelo estimado não atende aos pressupostos assintóticos do teste.

Tabela 5

Small-Hsiao: Teste para o Pressuposto da IIA

\begin{tabular}{l|c|c|c|c|c|c}
\hline Omitted & 1NCL(full) & 1NCL(omit) & $\mathbf{c h i}^{\mathbf{2}}$ & $\mathbf{d f}$ & $\mathbf{P}>\mathbf{c h i}^{\mathbf{2}}$ & Evidence \\
\hline CM & $-785,603$ & $-763,57$ & 44,065 & 63 & 0,967 & for H0 \\
CMB & $-844,615$ & $-821,578$ & 46,074 & 63 & 0,946 & for H0 \\
CT & $-780,872$ & $-754,74$ & 52,263 & 63 & 0,831 & for H0 \\
N & $-1042,258$ & $-1022,38$ & 39,756 & 63 & 0,99 & for H0 \\
\hline
\end{tabular}

Fonte: Pesquisa sobre a Classe Média 2008 (Banco de Dados, Cesop/Unicamp). Disponível em: http://www.cesop.unicamp.br/site/htm/busca/php. Acessado em 5/6/2012. Tabulação do próprio autor.

Nota: H0: Chances (Resultado-J em vez de Resultado-K) são independentes das demais alternativas. 
Tabela 6

Modelo Logit Multinomial para Identidades de Classe: Probabilidades Preditas e Intervalo de Confiança (95\%), por Tipos Sociais (Brasil, 2008)

\begin{tabular}{l|c|c|c}
\hline Tipo & Identidades de Classe & p. & Intervalo de Confiança (95\%) \\
\hline \multirow{4}{*}{ AB } & CM & 0,6818 & {$[0.5670,0.7965]$} \\
& CMB & 0,2401 & {$[0.1325,0.3478]$} \\
& CT & 0,0504 & {$[0.0108,0.0900]$} \\
& CB & 0,0212 & {$[0.0019,0.0404]$} \\
C & N & 0,0065 & {$[-0.0047,0.0178]$} \\
\hline \multirow{4}{*}{ D } & CMB & 0,3587 & {$[0.2526,0.4649]$} \\
& CT & 0,2463 & {$[0.1516,0.3410]$} \\
& CB & 0,2329 & {$[0.1423,0.3236]$} \\
& N & 0,1564 & {$[0.0946,0.2181]$} \\
& CM & 0,0057 & {$[-0.0009,0.0122]$} \\
\hline \multirow{4}{*}{ E } & CMB & 0,1971 & {$[0.1238,0.2705]$} \\
& CT & 0,1839 & {$[0.1075,0.2602]$} \\
& CB & 0,2738 & {$[0.1822,0.3655]$} \\
& N & 0,3171 & {$[0.2275,0.4066]$} \\
& CM & 0,028 & {$[0.0026,0.0535]$} \\
\hline
\end{tabular}

Fonte: Pesquisa sobre a Classe Média 2008 (Banco de Dados, Cesop/Unicamp). Disponível em: http://www.cesop.unicamp.br/site/htm/busca/php. Acessado em 5/6/2012. Tabulação do próprio autor.

\section{Tabela 7}

Modelo Multinomial para Identidades de Classe:

Intervalos de Confiança (95\%) para Variações Discretas nas Probabilidades

Preditas, por Tipos Sociais

(Brasil, 2008)

\begin{tabular}{l|c|c|c}
\hline \multirow{2}{*}{ Identidades de Classe } & \multicolumn{3}{|c}{ 95\% CI for Change } \\
\cline { 2 - 4 } & ABxC & CxD & DxE \\
\hline $\operatorname{Pr}(\mathrm{y}=\mathrm{CM}):$ & {$[0.1862,0.4427]$} & {$[0.0691,0.2294]$} & {$[0.0516,0.1857]$} \\
$\operatorname{Pr}(\mathrm{y}=\mathrm{CMB}):$ & {$[-0.1520,0.0922]$} & {$[0.0219,0.1832]$} & {$[0.0109,0.1507]$} \\
$\operatorname{Pr}(\mathrm{y}=\mathrm{CT}):$ & {$[-0.2432,-0.0855]$} & {$[-0.1507,0.0207]$} & {$[-0.0272,0.1591]$} \\
$\operatorname{Pr}(\mathrm{y}=\mathrm{CB}):$ & {$[-0.1667,-0.0669]$} & {$[-0.2400,-0.0914]$} & {$[-0.3522,-0.1558]$} \\
$\operatorname{Pr}(\mathrm{y}=\mathrm{N}):$ & {$[-0.0143,0.0075]$} & {$[-0.0426,0.0004]$} & {$[-0.0398,0.0169]$} \\
\hline
\end{tabular}

Fonte: Pesquisa sobre a Classe Média 2008 (Banco de Dados, Cesop/Unicamp). Disponível em: http://www.cesop.unicamp.br/site/htm/busca/php. Acessado em 5/6/2012. Tabulação do próprio autor. 
Gráfico 7

Práticas de Consumo por Tipologia

(Brasil, 2008)

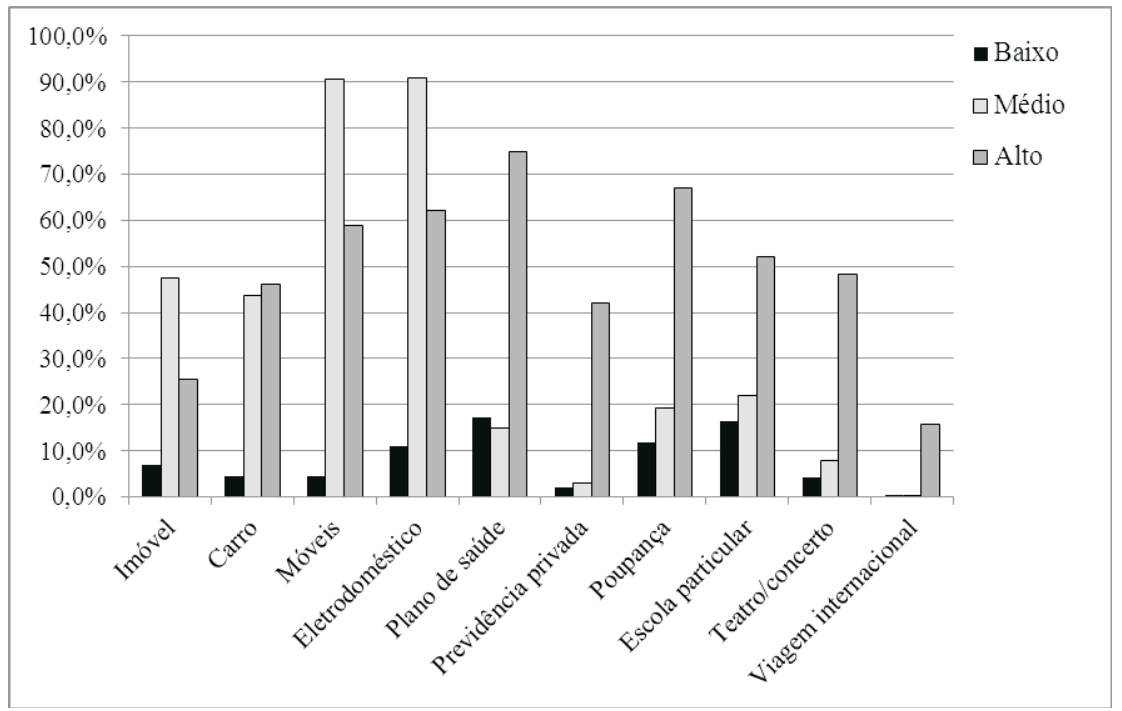

Fonte: Pesquisa sobre a Classe Média 2008 (Banco de Dados, Cesop/Unicamp). Disponível em: http://www.cesop.unicamp.br/site/htm/busca/php. Acessado em 5/6/2012. Tabulação do próprio autor.

\section{Gráfico 8}

Identidades de Classe por Níveis de Renda, Escolaridade, Categorias Ocupacionais e Tipologia de Consumo

(Brasil, 2008)

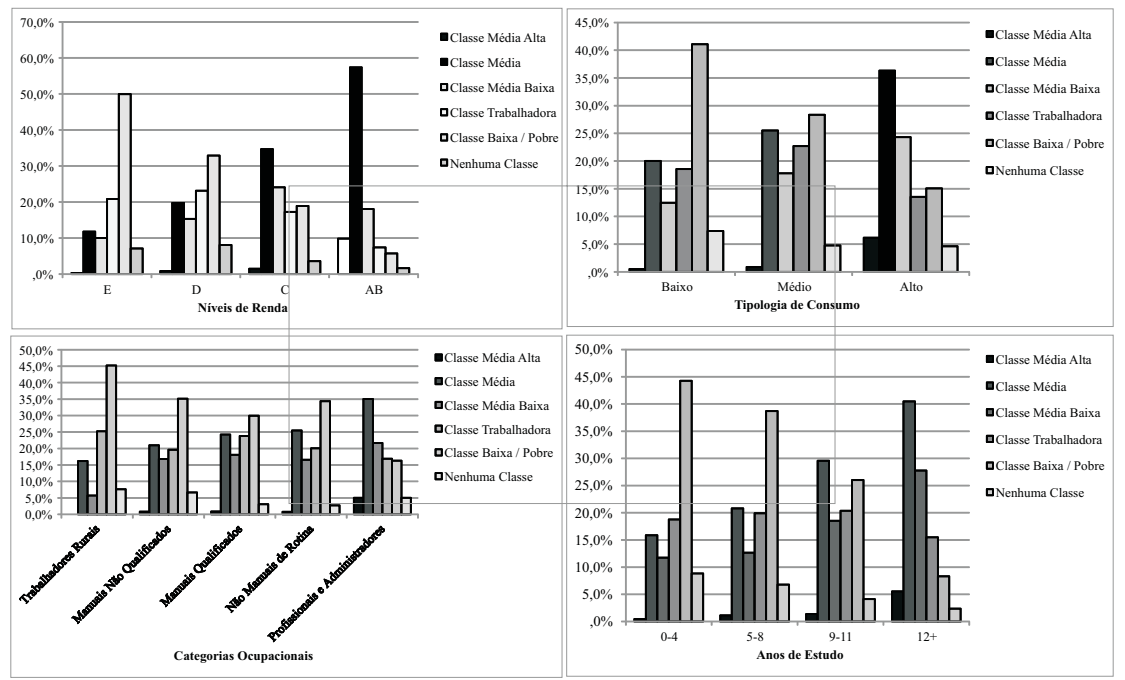

Fonte: Pesquisa sobre a Classe Média 2008 (Banco de Dados, Cesop/Unicamp). Disponível em: http://www.cesop.unicamp.br/site/htm/busca/php. Acessado em 5/6/2012. Tabulação do próprio autor.

DADOS - Revista de Ciências Sociais, Rio de Janeiro, vol. 58, nº 1, 2015 
RESUMO

Quem É Classe Média no Brasil? Um Estudo sobre Identidades de Classe

Este artigo busca contribuir para o debate atual sobre a classe média no Brasil, tendo como foco as identidades de classe e percepções dos brasileiros sobre a classe média. Na última década milhares de indivíduos atingiram níveis intermediários de renda, e passaram a fazer parte da camada mediana da população. No entanto, partimos da hipótese de que esses indivíduos não seriam aqueles que mais tipicamente se identificariam com essa classe. A fim de testá-la, trabalhamos com os dados provenientes da "Pesquisa sobre Classe Média" (Cesop/Unicamp, 2008), fazendo uso de estatísticas descritivas e modelos multivariados. Os resultados alcançados mostram que os indivíduos de perfil socioeconômico intermediário não são aqueles que habitualmente se percebem como classe média. De fato, é apenas entre aqueles mais privilegiados que podemos verificar uma identificação mais provável com esta classe. Além disso, também fica evidente que a imagem que se faz da classe média no Brasil diz respeito aos setores mais abastados, e não intermediários, da população.

Palavras-chave: classe média; identidades de classe; estratificação social; desigualdades sociais; percepções

\section{ABSTRACT}

Who is Middle Class in Brazil? A Study on Class Identities

This article seeks to contribute to the current debate on the middle class in Brazil, focusing on class identity and the perception of Brazilian concerning the middle class. In the last decade thousands have ascended tom mid-range income levels and became part of the middle layer of the population. However, the assumption is that these individuals are not those who typically identify with this class. To test it, descriptive statistics and multivariate models were applied to data from the "Pesquisa sobre Classe Média" (Cesop/Unicamp, 2008). The results achieved show that the individuals whose socioeconomic profile fall in the middle are not those who usually perceive themselves as middle class. In fact, a higher likelihood of identification with the middle class can only be verified among the more privileged. Furthermore, it also becomes evident that the image of the middle class constructed in Brazil applies to wealthier strata $\mathrm{pf}$ the population rather than intermediary ones.

Keywords: middle class; class identity; social stratification; social inequality; perceptions 
RÉSUMÉ

Qui Fait Partie des Classes Moyennes Brésiliennes? Une Étude sur les Identités de Classe

Cet article veut contribuer au débat actuel sur les classes moyennes brésiliennes en se penchant plus particulièrement sur les identités de classe et les perceptions des Brésiliens eux-mêmes quant aux classes moyennes. Lors de la dernière décennie, des milliers d'individus ont accédé à des niveaux intermédiaires de revenu et font maintenant partie des strates moyennes de la population. Nous partons néanmoins du principe que ces individus ne sont pas forcément ceux qui s'identifient le plus volontiers à ces classes. Afin de tester cette hypothèse, nous avons travaillé à partir de données provenant de la recherche "Pesquisa sobre Classe Média" (Cesop/Unicamp, 2008) et fait usage de statistiques descriptives et de modèles multivariés. Les résultats obtenus montrent que les individus au profil socioéconomique intermédiaire ne sont pas ceux qui se perçoivent habituellement comme faisant partie des classes moyennes. En effet, seuls les plus privilégiés d'entre eux s'y identifient plus largement. En outre, il est ressorti clairement que l'image la plus répandue des classes moyennes au Brésil se réfère plutôt aux secteurs les plus aisées, et non pas intermédiaires, de la population.

Mots-clés: classes moyennes; identités de classe; stratification sociale; inégalités sociales; perceptions

\section{RESUMEN}

¿Quién es Clase Media en Brasil? Un Estudio sobre Identidades de Clase

Este artículo busca contribuir al actual debate sobre la clase media en Brasil, adoptando como foco las identidades de clase y las percepciones de los brasileños sobre la clase media. En la última década, millares de individuos alcanzaron niveles intermediarios de renta y pasaron a componer la camada mediana de la población. Sin embargo, partimos de la hipótesis de que estos individuos no son aquellos que típicamente se identifican con dicha clase. Con el objetivo de corroborar esta presunción, utilizamos los datos provenientes de la "Pesquisa sobre Classe Média" (Cesop/Unicamp, 2008) a partir de la utilización de estadísticas descriptivas y modelos multivariados. Los resultados encontrados demuestran que los individuos de perfil socioeconómico intermediario no son aquellos que habitualmente se perciben como clase media. De hecho, es sólo entre aquellos más privilegiados donde verificamos una identificación más probable con esta clase. Asimismo, también queda claro que la imagen sobre la clase media en Brasil alude a los sectores más altos, y no intermediarios, de la población.

Palabras clave: clase media; identidades de clase; estratificación social; desigualdades sociales; percepciones 